Atmos. Chem. Phys., 10, 6969-6991, 2010

www.atmos-chem-phys.net/10/6969/2010/

doi:10.5194/acp-10-6969-2010

(C) Author(s) 2010. CC Attribution 3.0 License.

\title{
Oxidative capacity of the Mexico City atmosphere - Part 1: A radical source perspective
}

\author{
R. Volkamer ${ }^{1,2,3}$, P. Sheehy ${ }^{1,4}$, L. T. Molina ${ }^{1,4}$, and M. J. Molina ${ }^{1,2}$ \\ ${ }^{1}$ Department of Earth, Atmospheric and Planetary Sciences, Massachussetts Institute of Technology, Cambridge, MA, USA \\ ${ }^{2}$ Department of Chemistry and Biochemistry, University of California, San Diego, La Jolla, CA, USA \\ ${ }^{3}$ Department of Chemistry and Biochemistry and CIRES, University of Colorado at Boulder, Boulder, CO, USA \\ ${ }^{4}$ Molina Center for Energy and the Environment (MCE ${ }^{2}$ ), La Jolla, CA, USA
}

Received: 27 March 2007 - Published in Atmos. Chem. Phys. Discuss.: 18 April 2007

Revised: 5 March 2010 - Accepted: 23 April 2010 - Published: 30 July 2010

\begin{abstract}
A detailed analysis of $\mathrm{OH}, \mathrm{HO}_{2}$ and $\mathrm{RO}_{2}$ radical sources is presented for the near field photochemical regime inside the Mexico City Metropolitan Area (MCMA). During spring of 2003 (MCMA-2003 field campaign) an extensive set of measurements was collected to quantify timeresolved $\mathrm{RO}_{\mathrm{x}}$ (sum of $\mathrm{OH}, \mathrm{HO}_{2}, \mathrm{RO}_{2}$ ) radical production rates from day- and nighttime radical sources. The Master Chemical Mechanism (MCMv3.1) was constrained by measurements of (1) concentration time-profiles of photosensitive radical precursors, i.e., nitrous acid (HONO), formaldehyde $(\mathrm{HCHO})$, ozone $\left(\mathrm{O}_{3}\right)$, glyoxal $(\mathrm{CHOCHO})$, and other oxygenated volatile organic compounds (OVOCs); (2) respective photolysis-frequencies (J-values); (3) concentration time-profiles of alkanes, alkenes, and aromatic VOCs (103 compound are treated) and oxidants, i.e., $\mathrm{OH}-$ and $\mathrm{NO}_{3}$ radicals, $\mathrm{O}_{3}$; and (4) $\mathrm{NO}, \mathrm{NO}_{2}$, meteorological and other parameters. The $\mathrm{RO}_{\mathrm{x}}$ production rate was calculated directly from these observations; the MCM was used to estimate further $\mathrm{RO}_{\mathrm{x}}$ production from unconstrained sources, and express overall $\mathrm{RO}_{\mathrm{x}}$ production as $\mathrm{OH}$-equivalents (i.e., taking into account the propagation efficiencies of $\mathrm{RO}_{2}$ and $\mathrm{HO}_{2}$ radicals into $\mathrm{OH}$ radicals).

Daytime radical production is found to be about 10-25 times higher than at night; it does not track the abundance of sunlight. 12-h average daytime contributions of individual sources are: Oxygenated VOC other than HCHO about 33\%;
\end{abstract}

Correspondence to: R. Volkamer

(rainer.volkamer@colorado.edu)
$\mathrm{HCHO}$ and $\mathrm{O}_{3}$ photolysis each about 20\%; $\mathrm{O}_{3}$ /alkene reactions and HONO photolysis each about $12 \%$, other sources $<3 \%$. Nitryl chloride photolysis could potentially contribute $\sim 15 \%$ additional radicals, while $\mathrm{NO}_{2} *+$ water makes - if any - a very small contribution $(\sim 2 \%)$. The peak radical production of $\sim 7.510^{7}$ molec cm $\mathrm{cm}^{-3} \mathrm{~s}^{-1}$ is found already at 10:00 a.m., i.e., more than $2.5 \mathrm{~h}$ before solar noon. $\mathrm{O}_{3} /$ alkene reactions are indirectly responsible for $\sim 33 \%$ of these radicals. Our measurements and analysis comprise a database that enables testing of the representation of radical sources and radical chain reactions in photochemical models.

Since the photochemical processing of pollutants in the MCMA is radical limited, our analysis identifies the drivers for ozone and SOA formation. We conclude that reductions in VOC emissions provide an efficient opportunity to reduce peak concentrations of these secondary pollutants, because (1) about $70 \%$ of radical production is linked to VOC precursors; (2) lowering the $\mathrm{VOC} / \mathrm{NO}_{\mathrm{x}}$ ratio has the further benefit of reducing the radical re-cycling efficiency from radical chain reactions (chemical amplification of radical sources); (3) a positive feedback is identified: lowering the rate of radical production from organic precursors also reduces that from inorganic precursors, like ozone, as pollution export from the MCMA caps the amount of ozone that accumulates at a lower rate inside the MCMA. Continued VOC reductions will in the future result in decreasing peak concentrations of ozone and SOA in the MCMA.

Published by Copernicus Publications on behalf of the European Geosciences Union. 


\section{Introduction}

Air pollution is an increasingly important concern in the public health debate (Health Effects Institute, 2000). In Mexico City the number of deaths associated with anthropogenic air pollution is comparable to that from car accidents (Molina and Molina, 2002). Ozone $\left(\mathrm{O}_{3}\right)$ and fine particulate matter $\left(\mathrm{PM}_{2.5}\right.$, particles with a diameter smaller than 2.5 micrometers) are integral components of photochemical smog. There is no evidence of a "safe" threshold concentration for $\mathrm{O}_{3}$ or $\mathrm{PM}_{2.5}$ related health effects. $\mathrm{O}_{3}$ is known to cause inflammation in the respiratory tract, reduce respiratory capacity for some people, and increase hospitalization rates related to asthma and other respiratory ailments. More recently, systematic evidence has been presented supporting premature mortality in relation to short-term $\mathrm{O}_{3}$ exposure following episodes of photochemical smog in the US (Bell et al., 2004) and Asia (PAPA, 2004). Downwind of urban areas, photochemical $\mathrm{O}_{3}$ leads to reduced tree-growth (Gregg et al., 2003), has adverse effects on agriculture (Fuhrer and Booker, 2003), and contributes to global warming (IPCC, 2007). Short-term exposures to high levels of $\mathrm{PM}_{2.5}$ (e.g., $500 \mu \mathrm{g} / \mathrm{m}^{3}$ ) caused premature mortality during the London killer smog episode in 1952 (Davis et al., 2002); more recent studies in the US, Europe, Asia, and South America have further found association of long-term exposures to $\mathrm{PM}_{2.5}$ with premature mortality at much lower levels $\left(<50 \mu \mathrm{g} / \mathrm{m}^{3}\right)$ (Health Effects Institute, 2000; Pope et al., 2002). Recent progress toward identifying biological mechanisms for these effects point to the role of transition metals and pro-oxidative hydrocarbons associated with fine particulate matter (Nel, 2005). Enhanced light absorption by aerosols affects climate (Ramanathan et al., 2001) with implications for atmospheric stability and vertical air exchange, precipitation patterns, and the amount of radiation reaching the ground.

Photochemical smog is largely formed as the result of the chemical transformations of primary emissions to the atmosphere. It has long been understood that $\mathrm{O}_{3}$ is not directly emitted, but forms in the atmosphere as a result of hydrocarbon/ $/ \mathrm{NO}_{\mathrm{x}} /$ sunlight photochemistry (Haagen-Smit et al., 1951). On the other hand, it has only recently been recognized that in Mexico City and other urban areas - despite the abundance of emission sources - gas-to-particle conversion processes are responsible for about $60-80 \%$ of $\mathrm{PM}_{2.5}$ mass; secondary organic aerosol (SOA) originating from the gas-phase oxidation of hydrocarbons is a major component of $\mathrm{PM}_{2.5}$ (Salcedo et al., 2006; Volkamer et al., 2006; Zhang et al., 2007). Free radical (i.e., $\mathrm{OH}$ and $\mathrm{NO}_{3}$ ), $\mathrm{O}_{3}$, and photolysis reactions initiate the oxidation of hydrocarbons in the gas-phase, and possibly modify aerosol surfaces. The design of effective policy strategies to reduce the impact of air pollution on human health, ecosystem and climate requires understanding the sources and sinks of these radicals. Modeling studies (Ruiz-Suarez et al., 1993; West et al., 2004; Lei et al., 2007, 2008) and experimental observations (Arriaga-
Colina et al., 2004) suggest that the photochemical processing of pollutants in the MCMA is either VOC limited or suppressed by high $\mathrm{NO}_{\mathrm{x}}$ levels; indeed both of these chemical regimes may apply at different times (Lei et al., 2007, 2008; Stephens et al., 2008). In either case, the photochemical processing of pollutants is radical limited. This suggests that a more detailed understanding of radical sources can identify mechanisms to efficiently slow down photochemical smog formation, including $\mathrm{O}_{3}$ and SOA formation in the MCMA.

The chemical mechanisms that underlie atmospheric model predictions of ozone (and fine $\mathrm{PM}_{2.5}$ ) are simplified representations of a rather complex chemistry of the urban atmosphere. The result of such "chemical lumping" is that atmospheric models become heavily parameterized when addressing a specific target question (e.g., predicting ozone). However, the optimal parameterization is different for different atmospheric conditions (e.g., $\mathrm{VOC} / \mathrm{NO}_{\mathrm{x}}$ ratio); once a model has been optimized, it remains a challenge to predict ozone if atmospheric conditions change. There is a hidden uncertainty in "lumped" chemistry modules that can account for errors as large as 10-60\% in the predicted ozone as atmospheric conditions change (Carter et al., 2005; Bloss et al., 2005a, b; Stockwell et al., 2008). This chemical uncertainty is in addition to those caused by uncertainties in meteorology and emissions. It is comparable in magnitude, but often neglected for consideration. This paper series investigates this "hidden" uncertainty directly by means of a detailed chemical model that has a minimum amount of chemical lumping. The model explicitly represents the formation and sink reactions of $\mathrm{OH}, \mathrm{HO}_{2}$, and $\mathrm{RO}_{2}$ radicals (in sum termed $\mathrm{RO}_{\mathrm{x}}$ radicals), and thus does not suffer from changing experimental conditions. Part 1 of the series focuses on the production of $\mathrm{RO}_{\mathrm{x}}$ radicals from the reaction of closed shell molecules with sunlight (i.e., $\mathrm{HONO}, \mathrm{HCHO}, \mathrm{O}_{3}$, glyoxal, numerous other oxygenated VOC (OVOC)), and the dark reaction of alkenes with $\mathrm{O}_{3}$ and $\mathrm{NO}_{3}$ radicals. Most of these radical sources are constrained by observations. In Part 2 Sheehy et al. (2010) the experimental radical production rates from this work are combined with observations of $\mathrm{HO}_{\mathrm{x}}$ radicals (Shirley et al., 2006) to directly quantify (1) the amplification of radical sources from chemical radical chain reactions, and (2) to assess our current capability to predict radical chain reactions that largely determine the oxidation capacity. Since these radicals have lifetimes on the order of few milliseconds to seconds, the comparison of measured and predicted radical concentrations systematically minimizes uncertainty from air movements and emissions, and isolates the uncertainty inherent in our limited understanding of oxidative chemistry.

\section{Experimental}

As part of the MCMA-2003 field campaign, time-resolved production of $\mathrm{HO}_{\mathrm{x}}$ radicals released from the decomposition of closed shell molecules were quantified. A comprehensive 
set of instrumentation to characterize radical precursor concentrations, their respective photolysis frequencies, and oxidants $\left(\mathrm{OH}, \mathrm{O}_{3}, \mathrm{NO}_{3}\right)$ was based at a supersite located at the Centro Nacional de Investigación y Capacitación Ambiental (CENICA) in the central-southern part of the MCMA. An overview of typical pollutant concentrations at the CENICA site is compiled in Molina et al. (2007); campaign median concentrations were $86 \mathrm{ppb} \mathrm{NO}_{\mathrm{x}}$ during morning rush hour, $20 \mathrm{ppb} \mathrm{NO}_{\mathrm{x}}$ during afternoons, median peak concentrations of $115 \mathrm{ppbO}_{3}, 0.4 \mathrm{pptOH}$, and $40 \mathrm{ppt} \mathrm{HO}_{2}$ shortly after noon, $120 \mathrm{~s}^{-1} \mathrm{OH}$-reactivity (morning rush hour). Of the calculated contributions to the $\mathrm{OH}$ reactivity, $12 \%$ was due to $\mathrm{NO}_{\mathrm{x}}, 7 \%$ to $\mathrm{CO}, 4 \%$ to $\mathrm{HCHO}$ and $72 \%$ to VOCs (Shirley et al., 2006). The instruments that measured radical precursor molecules are described in the following sections; more than $75 \%$ of the overall rate of radical production is constrained by measurements here. A complete list of measurements used to constrain the MCM model as given in the Supplementary Material of Sheehy et al. (2010).

\subsection{Measurement techniques}

The radical precursor molecules $\mathrm{HONO}, \mathrm{HCHO}, \mathrm{O}_{3}$, and CHOCHO were measured by Long-Path Differential Optical Absorption Spectroscopy (LP-DOAS), acetaldehyde and acetone were measured by PTR-MS (Jobson et al., 2010), and the respective photolysis frequencies for these molecules were measured by spectroradiometry as described below. Alkenes and other hydrocarbons were measured by a Fast Isoprene Sensor (FIS) and VOC canister samples (Velasco et al., 2007), open path DOAS and FTIR (see below), and PTR-MS (Jobson et al., 2010).

\subsubsection{Long-Path Differential Optical Absorption Spectrometry (LP-DOAS)}

Two LP-DOAS instruments were deployed on the rooftop of the CENICA building. DOAS uses unique specific narrow-band $(<5 \mathrm{~nm})$ absorption structures in the visible spectral range to separate trace gas absorptions from broadband molecule and aerosol extinction in the open atmosphere (Platt, 1994). The DOAS\#1 light path was directed towards an antenna tower in a south-easterly direction at an average height of $16 \mathrm{~m}$ with a $430 \mathrm{~m}$ path length (total $860 \mathrm{~m}$ ). DOAS\#2 faced an array of retro reflectors at Museo Fuego Nuevo (Cerro de la Estrella) resulting in a total light-path of $4420 \mathrm{~m}$ and average $70 \mathrm{~m}$ above ground. Atmospheric spectra were recorded by sequentially projecting $40-$ $\mathrm{nm}$ (DOAS\#1) and 80-nm (DOAS\#2) wide wavelength intervals centered around $260 \mathrm{~nm}, 318 \mathrm{~nm}, 357 \mathrm{~nm}, 427 \mathrm{~nm}$ and $642 \mathrm{~nm}$ onto the 1024-element linear photodiode array detector; background spectra recorded within a few minutes were subtracted to correct for stray-light from the atmosphere. The average time-resolution for a full cycle of spectra ranged between $30 \mathrm{~s}-4 \mathrm{~min}$ (DOAS\#1), and 2-15 min (DOAS\#2), de- pending on the light extinction due to ozone (DOAS\#1), $\mathrm{NO}_{2}$ and aerosols (DOAS\#1 and DOAS\#2).

DOAS\#1 measured $\mathrm{O}_{3}, \mathrm{NO}_{2}, \mathrm{SO}_{2}, \mathrm{HONO}, \mathrm{HCHO}$, benzene, toluene, m-xylene, p-xylene, mono-substituted alkylbenzenes $\left(\mathrm{C}_{2}\right.$ and higher), phenol, p-cresol, and benzaldehyde by observing unique specific ro-vibronic absorption structures distributed over several hundred wavelength channels simultaneously. Naphthalene and styrene were also measured for the first time with DOAS in the atmosphere (Volkamer et al., 2004). Reference spectra of aromatic compounds were recorded by introducing quartz-cuvettes filled with vapor into the light beam, and these spectra were calibrated by using absorption cross-section spectra taken from the literature (Etzkorn et al., 1999). Absorptions of atmospheric oxygen were eliminated using the interpolation approach of Volkamer et al. (1998). In brief, saturation of molecular absorption lines of oxygen in the Herzberg I-III bands were modeled in high-resolution using line parameters from Fally et al. (2000), Jenouvrier et al. (1999) and Merienne et al. $(2000,2001)$, and oxygen column densities of $3.7 \times 10^{17}$ molecules $\mathrm{cm}^{-2}$ and $4.1 \times 10^{17}$ molecules $\mathrm{cm}^{-2}$ to bracket the effect of density variations on oxygen column densities. The collision induced absorption of oxygen in the Wulf bands was fitted using the literature spectra from Bernath et al. (1998). For ozone, temperature dependent absorption cross-sections (Bass and Paur, 1981) for $293 \mathrm{~K}$ and $313 \mathrm{~K}$ were convoluted to match the spectral resolution of the instruments, and fitted simultaneously with other tracegas reference spectra and a fifth order polynomial high-pass filter to account for broadband molecule and aerosol extinction using non-linear least squares fitting routines (Stutz et al., 1996; Fayt et al., 2001). The mean detection limits of species measured by DOAS\#1 were: $1.3 \mathrm{ppbv}\left(\mathrm{O}_{3}\right)$, $1.5 \mathrm{ppbv}\left(\mathrm{NO}_{2}\right), 0.26 \mathrm{ppbv}\left(\mathrm{SO}_{2}\right), 0.5 \mathrm{ppbv}$ (HONO), $5 \mathrm{ppbv}$ (HCHO), $1 \mathrm{ppbv}$ (benzene, toluene, m-xylene), $0.3 \mathrm{ppbv}$ (p-xylene), $1.8 \mathrm{ppbv}$ (ethylbenzene-equivalents), $0.5 \mathrm{ppbv}$ (styrene), $0.06 \mathrm{ppbv}$ (phenol, p-cresol), $0.2 \mathrm{ppbv}$ (benzaldehyde), and $0.08 \mathrm{ppbv}$ (naphthalene).

From the spectra collected by DOAS\#2, HCHO and ozone were evaluated in the wavelength range between 324 to $358 \mathrm{~nm}$ using non-linear least squares fitting of $\mathrm{HCHO}$, $\mathrm{HONO}, \mathrm{NO}_{2}$, two $\mathrm{O}_{3}$ references at $293 \mathrm{~K}$ and $313 \mathrm{~K}, \mathrm{SO}_{2}$, and a 5 th order polynomial high pass filter. HONO was retrieved in the wavelength range between 321 to $372 \mathrm{~nm}$ using non-linear least squares fitting of $\mathrm{HONO}, \mathrm{HCHO}, \mathrm{NO}_{2}$, two $\mathrm{O}_{3}$ references at $293 \mathrm{~K}$ and $313 \mathrm{~K}, \mathrm{SO}_{2}$, and a 9 th order polynomial high-pass filter. $\mathrm{CHOCHO}$ was retrieved from evaluating the spectral range between 420 and $465 \mathrm{~nm}$, using non-linear least squares fitting of $\mathrm{CHOCHO}, \mathrm{NO}_{2}, \mathrm{O}_{4}$, $\mathrm{H}_{2} \mathrm{O}$, two lamp-reference spectra, and a 5 th order polynomial high-pass filter; these data are discussed in more detail by Volkamer et al. (2005a). In addition, $\mathrm{NO}_{3}$ radicals were detected at nighttime. Reference spectra were calculated from high-resolution absorption cross-section spectra, which were degraded to our instrument resolution (ca. $0.4 \mathrm{~nm}$ 
Table 1. The percentage contributions of individual sources to $\mathrm{OH}_{\text {new }}$ (bold numbers). Individual molecules are differentiated by their source (italic numbers, add up to $100 \%$ for any given source); for "other OVOC" sources for $\mathrm{OH}_{\text {new }}$ from $\mathrm{HO}_{2}$ and $\mathrm{RO}_{2}$ radicals are differentiated (italic numbers), and differentiated by molecular functional groups (small roman numbers, add up to $100 \%$ in the $\mathrm{HO}_{2}$ and $\mathrm{RO}_{2}$ sub categories).

\begin{tabular}{|c|c|c|c|c|c|c|c|c|c|c|}
\hline & & \multicolumn{9}{|c|}{ contribution to $\Sigma \mathrm{OH}_{\text {new }}$} \\
\hline & & 03:00 & 07:00 & 09:00 & 11:00 & $13: 00$ & $15: 00$ & 20:00 & 06:00-18:00 (avg) & 20:00-04:00 (avg) \\
\hline \multirow{15}{*}{ 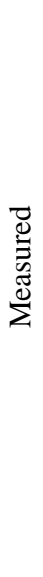 } & HONO & - & 42.1 & 21.8 & 7.4 & 3.9 & 1.1 & - & 11.8 & - \\
\hline & $\mathrm{PSS}^{\mathrm{a}}$ & - & $53-98$ & $91-99$ & $45-86$ & $53-92$ & $50-94$ & - & $80-90$ & - \\
\hline & Dark + other ${ }^{\mathrm{a}}$ & - & $\leq 47$ & $\leq 9$ & $\leq 55$ & $\leq 47$ & $\leq 50$ & - & $\leq 20$ & - \\
\hline & $\mathrm{O}_{3}$ & - & - & 4.0 & 21.7 & $\overline{36.4}$ & 29.7 & - & $\overline{19.2}$ & - \\
\hline & $\mathrm{HCHO}$ & - & 4.4 & 20.3 & 23.5 & 20.7 & 18.3 & - & 19.4 & - \\
\hline & Primary $\mathrm{b}, \mathrm{c}$ & - & 60.5 & 40.0 & 11.9 & 0.1 & 6.2 & - & 28.6 & - \\
\hline & Other $^{\mathrm{b}, \mathrm{c}}$ & - & 39.5 & 60.0 & 88.1 & 99.9 & 93.8 & - & 71.4 & - \\
\hline & $\mathrm{CH}_{3} \mathrm{CHO}$ & - & 0.1 & 0.5 & 0.8 & 1.0 & 1.4 & - & 0.8 & - \\
\hline & $\mathrm{CHOCHO}$ & - & 0.1 & 0.7 & 1.0 & 1.1 & 0.8 & - & 0.8 & - \\
\hline & $\mathrm{CH}_{3} \mathrm{COCH}_{3}$ & - & 0.1 & 0.2 & 0.3 & 0.4 & 0.4 & - & 0.3 & - \\
\hline & $\mathrm{O}_{3}+$ alkenes & 81.9 & 22.6 & 16.6 & 9.2 & 4.1 & 10.5 & 78.7 & 12.0 & 84.7 \\
\hline & $\rightarrow \mathrm{OH}^{\mathrm{c}}$ & 55.3 & 48.2 & 50.6 & 52.7 & 53.3 & 53.6 & 55.1 & 51.9 & 53.2 \\
\hline & $\rightarrow \mathrm{HO}_{2}^{\mathrm{c}}$ & 8.2 & 6.6 & 9.0 & 12.1 & 12.5 & 11.7 & 9.6 & 10.2 & 8.1 \\
\hline & $\rightarrow \mathrm{RO}_{2}^{\mathrm{c}}$ & 36.5 & 45.2 & 40.4 & 35.2 & 34.2 & 34.7 & 35.4 & 37.9 & 38.7 \\
\hline & $\mathrm{NO}_{2} *$ & - & 2.1 & 4.3 & 1.6 & 0.8 & 1.3 & - & 2.1 & - \\
\hline \multirow{18}{*}{ 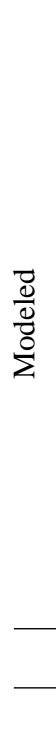 } & $\mathrm{ROOH}$ & - & 1.0 & 1.7 & 1.2 & 1.6 & 2.5 & - & 0.9 & - \\
\hline & $\rightarrow \mathrm{OH}$ & - & 4.3 & 4.9 & 23.3 & 62.6 & 70.6 & - & 62.6 & - \\
\hline & $\rightarrow \mathrm{RO}_{2}$ & - & 95.7 & 95.1 & 76.7 & 37.4 & 29.4 & - & 37.4 & - \\
\hline & other OVOC & - & 25.1 & 28.9 & 31.0 & 27.6 & 29.6 & - & 30.3 & - \\
\hline & $\rightarrow \mathrm{HO}_{2}^{\mathrm{c}}$ & - & 51.1 & 56.1 & 60.3 & 60.7 & 61.1 & - & 57.6 & - \\
\hline & carbonyls & - & 83.8 & 69.7 & 68.7 & 67.9 & 70.6 & - & 69.7 & - \\
\hline & $\mathrm{RCHO}$ & - & 2.7 & 10.6 & 18.8 & 22.5 & 16.8 & - & 16.4 & - \\
\hline & EPOX & - & 12.2 & 17.5 & 9.8 & 7.2 & 10.8 & - & 11.6 & - \\
\hline & Ketones & - & - & 0.2 & 0.5 & 0.8 & 0.6 & - & 0.5 & - \\
\hline & MISC & - & 1.3 & 2.1 & 2.5 & 1.4 & 1.0 & - & 1.7 & - \\
\hline & $\rightarrow \mathrm{RO}_{2}^{\mathrm{c}}$ & - & 47.8 & 42.2 & 38.8 & 38.7 & 38.2 & - & 42.4 & - \\
\hline & carbonyls & - & 94.2 & 85.7 & 81.3 & 80.5 & 84.8 & - & 83.5 & - \\
\hline & RCHO & - & 1.6 & 7.2 & 11.8 & 12.1 & 8.4 & - & 9.7 & - \\
\hline & Ketones & - & 0.3 & 1.7 & 3.7 & 5.2 & 4.4 & - & 3.4 & - \\
\hline & Misc & - & 2.3 & 1.6 & 1.0 & 0.7 & 0.5 & - & 1.0 & - \\
\hline & $\mathrm{NO}_{3}+\mathrm{VOC}$ & 18.1 & 0.2 & 1.1 & 2.1 & 1.9 & 3.8 & 21.3 & 2.2 & 15.3 \\
\hline & Sum $(\%)$ & 100.0 & 97.8 & 100.0 & 99.8 & 99.5 & 99.5 & 100.0 & 99.9 & 100.0 \\
\hline & $\Sigma \mathrm{OH}_{\text {new }}\left(\mathrm{ppbh}^{-1}\right)$ & 0.48 & 1.95 & 10.53 & 12.68 & 8.55 & 4.11 & 0.77 & 6.45 & 0.48 \\
\hline
\end{tabular}

a PSS: photostationary state HONO; dark+other: unaccounted HONO sources. Numbers indicate relative contributions to $\Sigma O \mathrm{H}_{\text {new }}$ from HONO; ${ }^{b}$ Primary: emission-related HCHO; other: photochemical and background HCHO (Garcia et al., 2006); ${ }^{\mathrm{c}}$ Numbers indicate relative contributions to $\Sigma \mathrm{OH}_{\text {new }}$ for a specific sub category of sources.

FWHM), and fitted using the Windoas and MFC software packages (Gomer et al., 1993; Fayt and van Roozendael, 2001). The trace-gas concentrations reported here rely on the following calibrations, with values in parentheses indicating mean detection limits for species measured by DOAS\#2: HONO (190 pptv) (Stutz et al., 2000), CHOCHO (150 pptv) (Volkamer et al., 2005b), $\mathrm{NO}_{3}$ (5 pptv) (Sander et al., 2006), $\mathrm{O}_{3}$ (DOAS\#1: 1.3 ppbv; DOAS\#2: 5 ppbv) (Bass and Paur, 1981), and $\mathrm{SO}_{2}$ (150 pptv) (Vandaele et al., 1994). For
HCHO (1 ppbv) the cross-section by Cantrell et al. (1990) was used for spectra evaluation; the concentrations were multiplied by 1.22 to reflect the results from cross-calibration of ultraviolet and infrared spectral parameters of $\mathrm{HCHO}$ (Volkamer et al., 2005 ${ }^{1}$ ). For $\mathrm{NO}_{2}(430 \mathrm{pptv})$, reference spectra were recorded by placing a 2 -cm long quartz-cuvette

\footnotetext{
${ }^{1}$ Volkamer et al., 2005, CP26 at http://www.colorado.edu/ chemistry/volkamer/publications/index.html
} 
into the light beam, which was filled previously with a mixture of approximately $1 \% \mathrm{NO}_{2} / \mathrm{N}_{2}$ to atmospheric pressure. The $\mathrm{HONO} / \mathrm{NO}_{2}$ ratio was determined from simultaneous fitting of resolution-adjusted literature cross-sections and any HONO contamination of the cuvette was corrected by subtracting an appropriately scaled HONO spectrum from the cuvette spectrum. This approach eliminates the possibility of HONO contaminated $\mathrm{NO}_{2}$ reference spectra; we successfully used it in cross-comparisons of the DOAS and LOPAP techniques (Kleffmann et al., 2006). $\mathrm{NO}_{2}$ concentrations were scaled to match the average of various $\mathrm{NO}_{2}$ reference spectra as determined by Orphal (2003). Trace-gas concentrations that were evaluated in different spectral ranges ( $\mathrm{HONO}, \mathrm{NO}_{2}, \mathrm{HCHO}$ and $\mathrm{O}_{3}$ ) were found to be independent of the spectral range used for evaluation (within error limits).

\subsubsection{Proton-Transfer-Reaction Mass-Spectrometry (PTR-MS)}

Acetaldehyde $\left(\mathrm{CH}_{3} \mathrm{CHO}\right)$ and acetone $\left(\mathrm{CH}_{3} \mathrm{COCH}_{3}\right)$ were measured by a PTR-MS (Jobson et al., 2010), which was co-located with the DOAS instruments at the CENICA rooftop, about $16 \mathrm{~m}$ above the ground. The PTR-MS sensitivity was determined with a multi-component compressed gas standard from Apel-Reimer Environmental (Denver, USA) containing acetaldehyde and acetone, among other hydrocarbons. The standard had a stated accuracy of $\pm 5 \%$ for oxygenated species, better than $5 \%$ for hydrocarbons, and multipoint calibrations were performed every couple of days. Additional measurements of alkenes by a Fast Isoprene Sensor, supplemented by gas-chromatography (GC-FID) analysis of canister samples are described in detail elsewhere (Velasco et al., 2007).

\subsubsection{Spectroradiometry}

Photolysis frequencies of HONO $\left(J_{\mathrm{HONO}}\right), \mathrm{HCHO}\left(J_{\mathrm{HCHO}}\right)$, $\mathrm{CH}_{3} \mathrm{CHO}\left(J_{\mathrm{CH}_{3} \mathrm{CHO}}\right), \mathrm{O}_{3}\left(J_{\mathrm{O}_{3}}\right), \mathrm{CHOCHO}\left(J_{\mathrm{CHOCHO}}\right)$,

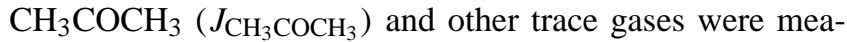
sured by spectroradiometry. The spectroradiometer was mounted on top of the measurement cabin with a clear field of view and measured solar actinic flux spectra from $280 \mathrm{~nm}$ to $450 \mathrm{~nm}$ with a spectral band pass of $1 \mathrm{~nm}$. The step width was set to $2 \mathrm{~nm}$ below $320 \mathrm{~nm}$, and $5 \mathrm{~nm}$ above. The radiation from the upper hemisphere was collected by a diffuseroptic with almost uniform sensitivity for all angles of incidence within a solid angle of $2 \pi$ sr. A double monochromator (Bentham DMc 150) equipped with a tunable grating (2400 grooves $/ \mathrm{mm}$ ) was used for wavelength dispersion and a photomultiplier for photon detection. The actinic flux calibration of the spectroradiometer was performed before and after the campaign at the Forschungszentrum Juelich in Germany using certified irradiance standards as described in Kraus et al. (2000). Unless otherwise noted, the ab-

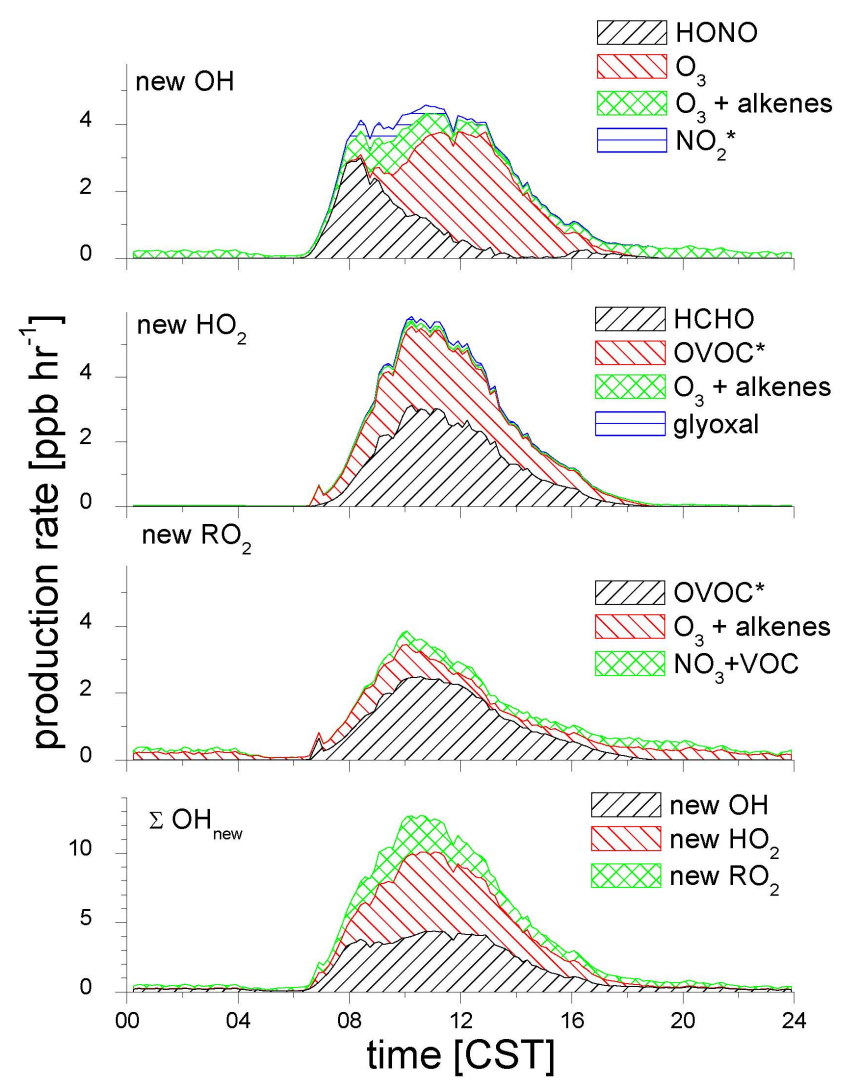

Fig. 1. Diurnal profiles of new $\mathrm{RO}_{\mathrm{x}}$ radical formation from different sources. The categories marked with a star (*) indicate that the reactants are not constrained by measurements. The bottom graph shows the contribution of each $\mathrm{RO}_{\mathrm{x}}$ species to $\Sigma \mathrm{OH}_{\text {new }}$, accounting for their respective conversion factors.

sorption cross-sections used to calculate photolysis frequencies were the same as described above; for $\mathrm{O}_{3}$, the crosssection at $295 \mathrm{~K}$ was employed; for HONO the current crosssection recommendation (Sander et al., 2006) was multiplied by 1.43 in order to match recent absolute measurements of $J_{\mathrm{HONO}}$ (Wall et al., 2006); for $\mathrm{CH}_{3} \mathrm{CHO}$ and $\mathrm{CH}_{3} \mathrm{COCH}_{3}$ the spectrum and quantum yield data for radical producing channels were taken from Sander et al. (2006). Resultant J-values were multiplied by 1.08 (surface albedo) to account for the upwelling portion of the photon actinic flux. The overall uncertainties for the photolysis channels are $25 \%$ for $\left(\mathrm{O}_{3} \rightarrow \mathrm{O}^{1} \mathrm{D}, \mathrm{CHOCHO} \rightarrow\right.$ radicals $)$, and $15 \%$ for $\left(\mathrm{HONO} \rightarrow \mathrm{OH}, \mathrm{HCHO}, \mathrm{CH}_{3} \mathrm{CHO}, \mathrm{CH}_{3} \mathrm{COCH}_{3} \rightarrow\right.$ radicals).

\subsection{Radical production rate calculations}

A flexible-top photochemical box model was used to calculate the radical production rates from experimentally constrained sources, and to estimate sources that were not constrained by observations. The model employs the Master Chemical Mechanism (MCM, v3.1), which is based on the 
protocols developed by Saunders et al. (2003) and Jenkin et al. (2003), and has recently been updated for aromatic oxidation schemes (Bloss et al., 2005a, b). MCM, a near-explicit mechanism comprising 135 VOCs and more than 13500 reactions, is ideally suited to test $\mathrm{RO}_{\mathrm{x}}$ radical production because it contains limited chemical lumping. This enables (1) accounting of individual radical production and loss pathways; and (2) expression of $\mathrm{RO}_{\mathrm{x}}$ radical production rates in terms of equivalent $\mathrm{OH}$ radical production rates as defined by Eq. (1):

$$
\Sigma \mathrm{OH}_{\text {new }}=P(\mathrm{OH})+\gamma_{\mathrm{HO}_{2}} \cdot P\left(\mathrm{HO}_{2}\right)+\gamma_{\mathrm{RO}_{2}} \cdot \gamma_{\mathrm{RO}} \cdot P\left(\mathrm{RO}_{2}\right)
$$

where $\mathrm{P}$-values represent the rate of production of $\mathrm{OH}, \mathrm{HO}_{2}$ and $\mathrm{RO}_{2}$ radicals from closed shell molecules, and gamma values represent the efficiency to propagate $\mathrm{RO}_{2}$ and $\mathrm{HO}_{2}$ radicals into $\mathrm{OH}$ radicals; $\gamma_{\mathrm{HO}_{2}}, \gamma_{\mathrm{RO}_{2}}$, and $\gamma_{\mathrm{RO}}$ are defined in Eqs. (6-8) in Sheehy et al. (2010), and are calculated by the $\mathrm{MCM}$ as a function of changing experimental conditions, i.e., $\mathrm{NO}, \mathrm{NO}_{3}, \mathrm{HO}_{2}, \mathrm{RO}_{2}$ concentrations, and VOC speciation.

The box-model was constrained by median time-profiles of the above radical precursor concentrations, J-values, oxidant concentrations $\left(\mathrm{OH}, \mathrm{HO}_{2}, \mathrm{O}_{3}, \mathrm{NO}_{3}\right)$, and concentrations of radical sinks, i.e., 103 VOCs, $\mathrm{NO}, \mathrm{NO}_{2}, \mathrm{SO}_{2}, \mathrm{CO}$ (Sheehy et al., 2010, Supplementary Information). The $\mathrm{OH}$ reactivity of the constrained model reproduced well the diurnal variations of $\mathrm{OH}-$ reactivity observations (Shirley et al., 2006), and were generally somewhat lower (see Part 2). The loss mechanisms of secondary species formed via the oxidation of hydrocarbons include reaction with $\mathrm{OH}$ radicals, $\mathrm{NO}_{3}$ radicals, $\mathrm{O}_{3}$, sunlight, and dilution. The dilution term was estimated in two ways: (1) using $\mathrm{CO}$ as a tracer for dilution in the rising planetary boundary layer (PBL) and pollution export from the MCMA (Garcia et al., 2006), and negligible dilution during the night (this method lead to chemical accumulation of oxidation products in the code and is considered a lower limit for dilution); (2) to overcome chemical accumulation in the afternoon and at night, additional dilution was calculated to match predictions of photochemical HCHO with observations (see Sect. 2.4).

HONO photolysis is calculated as the absolute radical flux from HONO photolysis rather than reflecting net-production (i.e., $\mathrm{HONO}$ photolysis flux minus the flux from the $\mathrm{OH}+\mathrm{NO}$ recombination reaction). We feel this is justified because even a negative net radical flux from HONO could still have a positive effect on photochemical radical cycling and ozone formation. This is because the fate of an $\mathrm{OH}$ radical is determined primarily by VOC reactions, and only a small portion reacts with $\mathrm{NO}$; a newly formed $\mathrm{OH}$ radical thus adds efficiently to the production of $\mathrm{RO}_{2}$ and $\mathrm{HO}_{2}$ that recycle $\mathrm{OH}$ multiple times before they are removed, and add to the formation of ozone. The net rate of ozone formation due to HONO can hence still be positive, even though the netproduction of $\mathrm{OH}$ from $\mathrm{HONO}$ might be negative. Accounting for $\mathrm{HONO}$ on a net-flux basis would not account for this chemical amplification of radical fluxes from HONO. We accounted for HONO on an absolute flux basis for two reasons: (1) this definition does justice to the true role of HONO to jump start photochemistry during morning hours; and (2) this definition allows us to quantitatively define the concept of "chain length" as the amplification of radical source fluxes (this paper) to radical recycling fluxes (Part 2, Sheehy et al., 2010). It turns out that an $\mathrm{OH}$ radical that is produced in the early morning hours is re-cycled about 3-4 times before it is removed by radical sink processes.

In principle, a similar argument could be made for the radical source from the thermal decomposition of Peroxy Acetyl Nitrate (PAN). We have calculated the radical production from PAN, and find that in this urban environment much more PAN is formed than dissociates, to the point that even accounting for chemical amplification of PAN formation is almost exclusively a net radical sink in the near field chemical regime inside the MCMA; hence we have not considered PAN as a radical source. OH radical production rates from the reaction $\mathrm{NO}_{2} *+\mathrm{H}_{2} \mathrm{O} \rightarrow \mathrm{OH}+\mathrm{HONO}$ was calculated as $P(\mathrm{OH})_{\mathrm{NO}_{2} *}=\mathrm{NO}_{2} \cdot J\left(\mathrm{NO}_{2} *\right) \cdot q$, where $J\left(\mathrm{NO}_{2} *\right)$ is the non-destructive excitation rate of $\mathrm{NO}_{2}$, determined from our spectroradiometer data, and $q=0.001$. $k_{\mathrm{H}_{2} \mathrm{O}} \cdot\left[\mathrm{H}_{2} \mathrm{O}\right] /\left(k_{\mathrm{H}_{2} \mathrm{O}} \cdot\left[\mathrm{H}_{2} \mathrm{O}\right]+k_{\mathrm{O}_{2}} \cdot\left[\mathrm{O}_{2}\right]+k_{\mathrm{N}_{2}} \cdot\left[\mathrm{N}_{2}\right]\right)$ is the fraction of $\mathrm{NO}_{2} *$ collisions with water and air molecules that leads to $\mathrm{HONO}$ and $\mathrm{OH}$ as products; rate constant values are $k_{\mathrm{H}_{2} \mathrm{O}}=1.7 \times 10^{-10}$ molec $\mathrm{cm}^{-3} \mathrm{~s}^{-1}, k_{\mathrm{O}_{2}}=3.0 \times$ $10^{-11}$ molec cm $^{-3} \mathrm{~s}^{-1}, k_{\mathrm{N}_{2}}=2.7 \times 10^{-11} \mathrm{molec} \mathrm{cm}^{-3} \mathrm{~s}^{-1}$ (Li et al., 2008, P. Wine, personal communication, 2007). Notably the $\mathrm{OH}$ radical production from further photolysis of any HONO that may form from $\mathrm{NO}_{2} *$ is accounted among the $\mathrm{OH}$ source from $\mathrm{HONO}$.

In order to estimate the nighttime radical production rates from $\mathrm{O}_{3}$ and $\mathrm{NO}_{3}$ reactions with alkenes, two scenarios were considered: (1) $\mathrm{O}_{3}$ constrained (DOAS\#1), $\mathrm{NO}_{3}$ unconstrained; and (2) $\mathrm{O}_{3}$ and $\mathrm{NO}_{3}$ constrained by observations. One complication arises from the different sampling altitudes for VOCs, and the mean height of DOAS\#2 light beam; vertical gradients in $\mathrm{O}_{3}$ and $\mathrm{NO}_{3}$ concentrations are most pronounced at night, and quickly disappear $1-2 \mathrm{~h}$ after sunrise. In order to account for vertical gradients in $\mathrm{NO}_{3}$ radicals (Fig. 2, and Sect. 2.3), as a first-order approximation the observed $\mathrm{NO}_{3}$ by DOAS\#2 was scaled to the altitude of DOAS\#1, using a linear scaling factor that was calculated from differences in $\mathrm{O}_{3}$ as observed between DOAS\#1 and DOAS\#2 $\left(\left[\mathrm{NO}_{3}\right]_{16 \mathrm{~m}}=\left[\mathrm{NO}_{3}\right]_{\text {DOASH2 }} \cdot\left[\mathrm{O}_{3}\right]_{\text {DOAS\#1 }} /\left[\mathrm{O}_{3}\right]_{\text {DOASH2 }}\right)$. The $\mathrm{O}_{3}$ data measured by both LP-DOAS are shown in Fig. 3. The scaled $\mathrm{NO}_{3}$ concentrations were on average about a factor of 3 lower (nighttime $8 \mathrm{~h}$ average concentration of 1.5 pptv), and are regarded as an upper limit of the true concentration at the height of DOAS\#1 since nonlinear feedbacks are not accounted for. We further base our discussion of $\mathrm{NO}_{3}$ radicals on the (unverified) assumption that similar VOC concentrations are present in $\mathrm{NO}_{3}$-rich and 


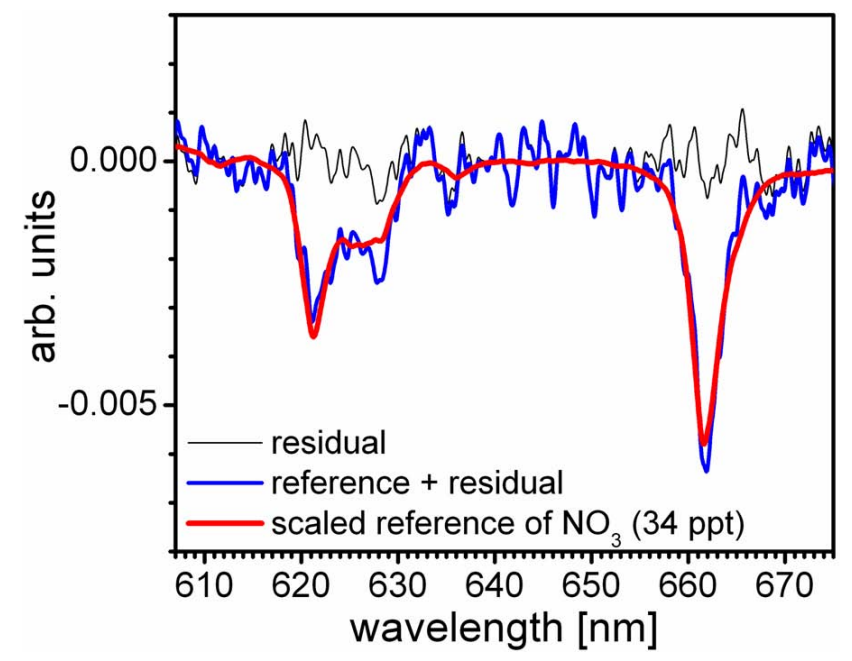

Fig. 2. Spectral proof for the detection of $\mathrm{NO}_{3}$ radicals in Mexico City (29 April 2003, 01:17 a.m. CST). The atmospheric spectrum (blue line) has been corrected for $\mathrm{NO}_{2}$, and water absorptions, and shown with an accordingly scaled $\mathrm{NO}_{3}$-reference spectrum (red line) from our previous work.

$\mathrm{NO}_{3}$-depleted air masses. As reactive unsaturated VOCs are expected to be depleted in $\mathrm{O}_{3}$ - and $\mathrm{NO}_{3}$-rich air, this assumption is compatible with an upper limit estimate of the role of $\mathrm{NO}_{3}$ radicals as a source for $\mathrm{RO}_{\mathrm{x}}$ radicals at the rooftop level. These uncertainties were minimized by constraining the box-model with data collected at roof-top level (also DOAS\#1 height). Finally, the sensitivity of the model towards statistical artifacts was tested by constraining with (1) average, and (2) median time-profiles of the above measurements; the results agreed within $10 \%$ at daytime, whereas larger differences were observed at night (see Sect. 3.3). Unless otherwise noted the results are reported from the model constrained by the median time series data.

\subsection{Characterization of horizontal and vertical gradients}

A possible complication in constraining the MCM model might arise from the fact that measurements used to constrain the model are conducted over extended spatial scales (LPDOAS, FTIR) and in the form of highly localized "point" measurements (e.g., PTR-MS). The direct comparison of radical fluxes inferred from these measurements is based on the assumption that the air mass is well mixed. This assumption is tested below, and appears to be justified for the following reasons. Spatial gradients are expected to be strongest for primary pollutants (e.g., CO) and somewhat less pronounced for secondary pollutants (e.g., $\mathrm{O}_{3}$ ). Sampled concentrations of $\mathrm{CO}$ and $\mathrm{O}_{3}$ at comparable heights by point and line-averaging techniques at the CENICA supersite show excellent agreement (Dunlea et al., 2006). Further, concentrations of several species that were probed by

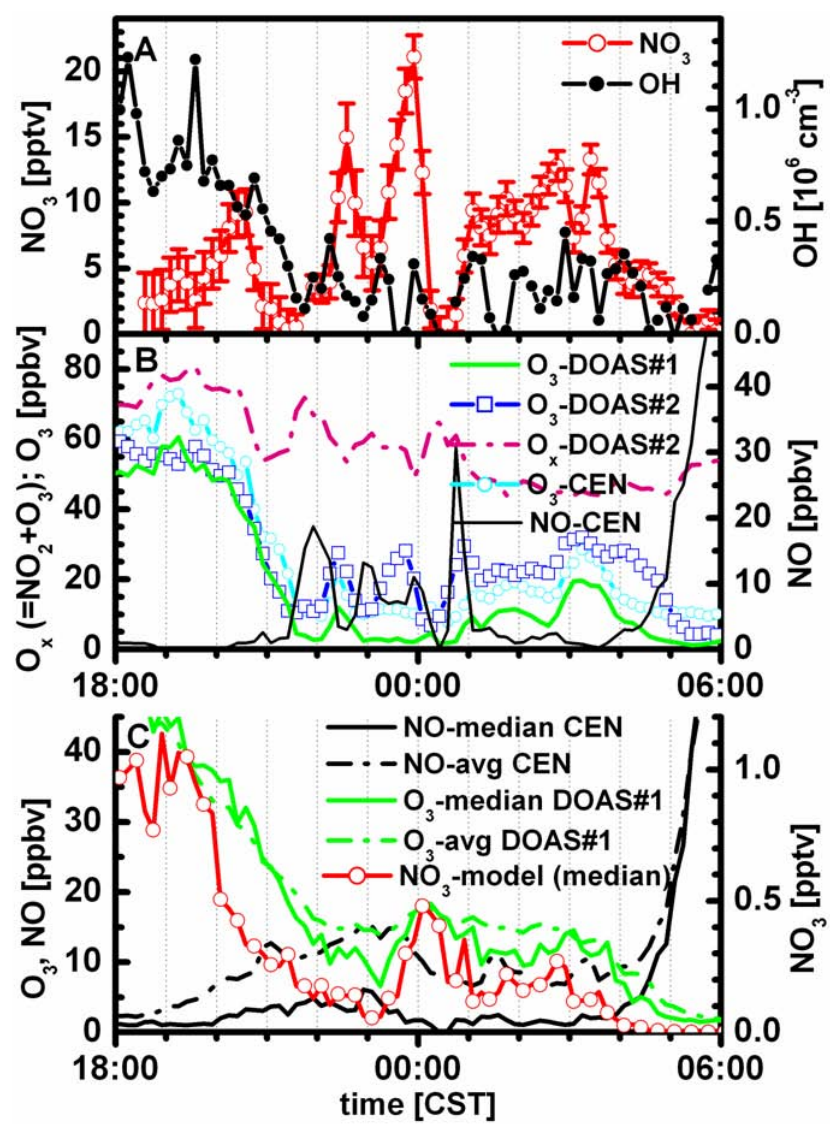

Fig. 3. Nighttime concentration-time profiles of $\mathrm{NO}_{3}$ radicals and $\mathrm{OH}$ radicals during the night from 25 to 26 April 2003 (A), $\mathrm{O}_{3}$ (from two LP-DOAS and a point sensor), $\mathrm{O}_{\mathrm{x}}$ (sum of $\mathrm{O}_{3}$ and $\mathrm{NO}_{2}$ ) and $\mathrm{NO}(\mathbf{B})$. Panel $\mathrm{C}$ compares average and median nighttime $\mathrm{O}_{3}$ and $\mathrm{NO}$ concentrations, and shows $\mathrm{NO}_{3}$ radical predictions from the median model. The nighttime $\mathrm{OH}$ concentration tends to follow the time trace of $\mathrm{O}_{3}$ better than that of $\mathrm{NO}_{3}$ radicals.

both open-path DOAS instruments facing in different directions, spanning different spatial scales and sampling at different mean heights show excellent agreement during the day (within measurement precision). For example, HONO was measured by two LP-DOAS instruments at $16 \mathrm{~m}$ and $70 \mathrm{~m}$ above ground, and vertical gradients are observed at nighttime and in the early morning. However, the data from both instruments have converged to within measurement precision already $1.5 \mathrm{~h}$ after sunrise (06:00 a.m. CST), as illustrated for HONO in Fig. 4. During the daytime, which is the primary focus of this study, the air mass is thus considered to be well mixed.

At night, mixing is driven by the heat-island effect (Jauregui, 1993; Oke et al., 1999) and large-scale eddy turbulence from mechanical sheering of winds aloft which can lead to horizontal and vertical gradients in trace-gas concentrations. Comparison of the measurements from the two LP-DOAS instruments with point sampling techniques set the limits on 

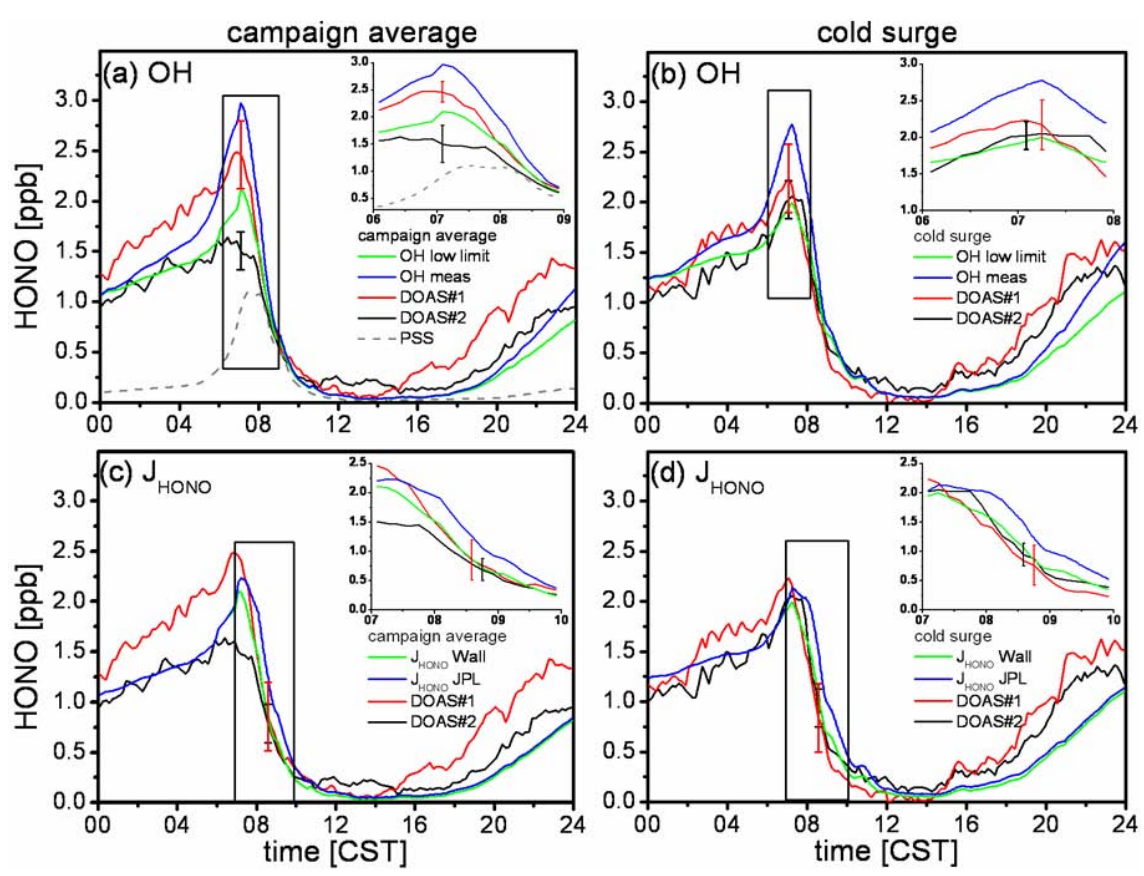

Fig. 4. Measured (red, black) and calculated (green, blue) HONO concentrations. Shown are campaign-averaged data (a, c) and data averaged over cold-surge events $(\mathbf{b}, \mathbf{d})$. The top two graphs show that varying $\mathrm{OH}$ within uncertainty (lower limit) improves the model measurement agreement in the early morning. The bottom two graphs show that model predicted HONO is systematically higher than the observations during mid- morning; an additional HONO sink is needed. Use of a higher value of $J_{\text {HONO }}$ according to Wall et al. (2006) improves the agreement between measured and modeled HONO concentrations significantly.

this inhomogeneity (see Figs. 3 and 4). Significant vertical gradients are observed for HONO and ozone. In an attempt to minimize the effect of vertical gradients on the prediction of secondary sources we chose to interpolate vertical gradients in oxidants to assure that constraints to the MCM model are at a comparable height $\left(\mathrm{OH}, \mathrm{O}_{3}, \mathrm{NO}_{3}\right)$. For the most precise measurements of low $\mathrm{O}_{3}$ concentrations, we use direct measurements from DOAS\#1 (for a discussion of possible interference issues with indirect techniques see Dunlea et al., 2006). $\mathrm{NO}_{3}$ radical concentrations at higher altitudes are adjusted here to roof level (Sect. 2.2). Figure 3a illustrates the significant variability in $\mathrm{NO}_{3}$ concentrations in our lineaveraged detection of several kilometers spatial scale. Periods of steeply rising $\mathrm{NO}$ concentrations are followed by periods when essentially no $\mathrm{NO}_{3}$ is observed. Also shown are the $\mathrm{O}_{3}$ concentrations measured by both LP-DOAS and a point-sensor, the sum of $\mathrm{NO}_{2}$ and $\mathrm{O}_{3}\left(\mathrm{O}_{\mathrm{x}}\right.$, from DOAS\#2), and NO during that night (Fig. 3b). The good agreement in the relative variation between the point-sensor and DOAS\#1, which are located at comparable altitudes, illustrates that at night the air mass is relatively homogeneous over horizontal spatial scales on the order of few $430 \mathrm{~m}$. The 5-10 ppbv offset in the point sensor is probably not real, as is discussed in Dunlea et al. (2006).

\section{Implications of nighttime inhomogeneities for the MCM model}

The simultaneous presence of $\mathrm{O}_{3}$ and $\mathrm{NO}$ in the same air mass has implications for $\mathrm{RO}_{2}$-to-OH conversion efficiencies, predicted $\mathrm{NO}_{3}$-radical concentrations, and, to a lesser extent, $\mathrm{OH}$ production rates. Figure $3 \mathrm{c}$ shows the comparison of the median and average concentration time profiles of $\mathrm{O}_{3}$ (DOAS\#1) and NO (point sensor). During the day there is virtually no difference between the average and median profiles, reflecting efficient mixing. At night, median concentrations are systematically lower for both $\mathrm{O}_{3}$ and $\mathrm{NO}$. The difference is larger for $\mathrm{NO}$ (a factor to 5-8) than for $\mathrm{O}_{3}$ $(10-80 \%)$, and reflected in the predicted $\mathrm{NO}_{3}$-radical concentration at the roof-top-level (about five times higher; median $\mathrm{NO}_{3}$ concentrations are shown in Fig. 3c). The average lifetime of $\mathrm{O}_{3}$ with respect to NO reactions at night is considerably longer in the median model (about $15 \mathrm{~min}$; compared to about $2.5 \mathrm{~min}$ in the average model), i.e., long enough that the presence of both $\mathrm{O}_{3}$ and NO in the same airmass is feasible based on their respective reactivity. Based on these results we prefer the median model for estimates of $\Sigma \mathrm{OH}_{\text {new }}$, which is reduced by one-third at night compared to the average model. 


\subsection{Source apportionment of photochemical HCHO calculations}

We attempted to identify the relevance of different classes of $\mathrm{VOC}$ to the photochemical production of $\mathrm{HCHO}$. We used the above-mentioned box model, without the HCHO constraint, to predict the rate of $\mathrm{HCHO}$ production from hydrocarbon oxidation chemistry during mid-morning conditions. The model was initiated using a constrained VOC split as given in the Supplementary Information of Sheehy et al. (2010), and oxidant and light conditions were kept constant: $[\mathrm{OH}]=0.18 \mathrm{pptv},\left[\mathrm{O}_{3}\right]=55 \mathrm{ppbv}$ and $J_{\mathrm{NO}_{2}}=5 \times 10^{-3} \mathrm{~s}^{-1}$. The fate of peroxy radicals is about $90 \%$ determined by reactions with NO in our model, which is consistent with the modeling of field data at peak photochemical productivity during mid-morning hours (see Fig. 6 in Sheehy et al., 2010). In a first set of model runs, the contributions from individual VOC classes as HCHO precursors were calculated by tracking the rate of $\mathrm{HCHO}$ production and varying the VOC split; only a single VOC class was set to nonzero, while the other VOC concentrations were set to zero. Second, to determine the relative contribution of individual oxidants, the rate of $\mathrm{HCHO}$ production was calculated with only that oxidant i.e., $\mathrm{OH}, \mathrm{O}_{3}, \mathrm{NO}_{3}$; the other oxidant concentrations were set to zero; identical sets of VOC and kinetic parameters were used. Third, to calculate the percentage of $\mathrm{HCHO}$ production as a first or higher generation VOC oxidation product, the yield of photochemical $\mathrm{HCHO}$ was compared after $10 \mathrm{~min}$ and several hours of oxidation (see Volkamer et al. (2001) for details on the argument). Only a small increase in the rate of $\mathrm{HCHO}$ production was observed over extended oxidation times, indicating that some $\mathrm{HCHO}$ is indeed produced as a higher generation oxidation product from OVOC oxidation, but this fraction is rather small (16\%). Most HCHO predicted from the MCM is thus formed as a first generation oxidation product. For most VOCs that are constrained in the model from the MCMA-2003 dataset, the formation of HCHO has been studied in the laboratory. The chemical pathways represented in the MCM are thus largely based on experimental constraints, and only a minor portion of predicted $\mathrm{HCHO}$ is expected to be formed from pathways that might be subjected to the more uncertain structure-reactivity relationships that (to a larger extent) underlie the MCM representation of OVOC oxidation.

Sensitivity studies using the flexible top MCM box model revealed that predicted $\mathrm{HCHO}$ accumulated to unrealistic concentrations later in the day. This prompted us to investigate whether the cause of this overestimation in the afternoon was due to uncertain chemical pathways that form $\mathrm{HCHO}$ in the model, or to an underestimate of pollution export (dilution). Photochemical sources from HCHO turned out to be well constrained (see above, and also Sect. 3.5). It was concluded to adjust the dilution sink of HCHO in the model to bring predicted $\mathrm{HCHO}$ in the later day into agreement with the photo- chemically formed portion of observed
HCHO (Sect. 3.5). We used a modified Eq. (1) in Garcia et al. (2006) to calculate the photochemically formed portion of ambient HCHO: $[\mathrm{HCHO}]_{\text {phot }}=[\mathrm{HCHO}]_{\text {meas }}-0.0015 \cdot[\mathrm{CO}]$, where the latter term represents a scaled tracer for $\mathrm{HCHO}$ emissions according to results from Garcia et al. (2006). The additional dilution reduced the afternoon $\mathrm{HCHO}$ by a factor of about 2 .

\subsection{Source apportionment of HONO calculations}

The sources of HONO investigated include photo-stationarystate HONO (PSS-HONO; under equilibrium conditions $\left.\mathrm{PSS}-\mathrm{HONO}=k \cdot \mathrm{OH} \cdot \mathrm{NO} / J_{\mathrm{HONO}}\right)$, dark sources from the $\mathrm{OH}+\mathrm{NO}$ recombination reaction, heterogeneous formation on urban surfaces, or aerosols, and photochemical sources. The MCM model is constrained by measurements of $\mathrm{OH}$, $\mathrm{NO}, J_{\mathrm{HONO}}$, dilution, and we used the model to calculate PSS-HONO. Nighttime $\mathrm{OH}$ only explained a small increase in HONO concentrations over the course of a night, and an additional HONO source was parameterized as a $\mathrm{NO}_{2} \rightarrow \mathrm{HONO}$ conversion rate to match the HONO production between 08:00 p.m. to 04:00 a.m.; this "dark-HONO" source was then applied throughout the day.

We employed the box model in the following three scenarios: inputs are constrained based on (1) campaign average concentration time-profiles, and (2) median concentration time-profiles. In an additional model scenario (3), only data from "cold-surge" days were averaged (de Foy et al., 2005), which are characterized by the highest relative humidity and the lowest PBL height. The highest daytime HONO concentrations are expected during such "cold-surge" events, as HONO concentrations have been shown to correlate with relative humidity (Stutz et al., 2004). For each of the three model scenarios, the sensitivity of the model output was tested by varying the $\mathrm{OH}$ concentration within measurement uncertainty (offset of 0.01 pptv was subtracted), varying the dilution case, and varying $J_{\mathrm{HONO}}$ within twice the experimental uncertainty (multiplication of J-value based on (Stutz et al., 2000) by 1.43 reproduces our observations, and is in general agreement with recent direct measurements of $J_{\text {HONO }}$ by Wall et al. (2006) that indicate scaling by a factor of 1.28). Any photochemical sources are evaluated as the difference to model predicted and "observed" daytime HONO. The model generally predicted HONO concentrations that were consistent with measured concentrations in the morning.

\subsection{Radical production from oxygenated VOC (OVOC) photolysis}

Selected OVOC such as $\mathrm{HCHO}, \mathrm{CHOCHO}$ and $\mathrm{CH}_{3} \mathrm{CHO}$, and their respective photolysis frequencies were measured during MCMA-2003. Other OVOC, a complex mixture of several hundred VOC reaction products, were estimated using the MCM model. The radical initiated OVOC loss is 
neutral in terms of radical production, since in principle the radical that is consumed by initiating the oxidation leads to the formation of another radical (i.e., a $\mathrm{RO}_{2}$ radical). On the other hand, OVOC photolysis converts a closed shell OVOC molecule into two radicals and is an efficient radical source. The model was constrained using measurements of $J\left(\mathrm{NO}_{2}\right)$ and the other photolysis parameters were parameterized relative to $J\left(\mathrm{NO}_{2}\right)$ in the model.

In Table 1 the production of $\mathrm{OH}, \mathrm{HO}_{2}$ and $\mathrm{RO}_{2}$ from OVOC photolysis is tracked using the constrained MCM model (for details see Part 2), and summed for a number of compound classes, i.e., aldehydes, multifunctional carbonyls, epoxides, ketones, and other miscellaneous OVOC. Aldehydes (RCHO in Table 1) are counted as the reaction of (multifunctional) carbonyls with only one end standing carbonyl group. The photolysis happens at the end-standing carbonyl group (associated with J-values 11, 15, and 17 in the MCM code). This group does not include HCHO, which is constrained in the model, and represented separately in Table 1 (see above). Carbonyls are counted as the flux from more complex molecules, which typically have 2 or 3 carbonyl groups, and photolysis is associated with J-values 4, 34 , and 35 in MCM. This group includes dicarbonyls other than glyoxal, which is constrained in the MCM and represented separately in Table 1. Epoxides (EPOX) are characterized as compounds with more than one functional group; however, photolysis occurs at the epoxy functional group (note that both dicarbonyls and epoxides are associated with $\mathrm{J}$-value 4 in the MCM, and our lumping actually considers the structure of the molecule as a means to differentiate the lumping). Ketones (KETO) are grouped as compounds that generally have more than one functional group; however, the photolysis occurs at the ketone group. This group is associated with J-value 22 in the MCM code. Other miscellaneous OVOC (MISC) are compounds that photolyze with J-values 18 and 19. Hydroperoxides (ROOH) are lumped as the flux from reactions that photolyze with a J-value 41 .

The radical fluxes from OVOC are taken from the MCM model that applied the increased dilution rate scaled from photochemical HCHO (Sect. 2.4) to all other predicted OVOCs.

\section{Results and discussion}

\subsection{OH-equivalent $\mathrm{RO}_{\mathrm{x}}$ radical production rates}

The calculated production for new $\mathrm{RO}_{\mathrm{x}}$ from the $\mathrm{HO}_{\mathrm{x}}$ constrained box model is shown in Fig. 1. The total radical production rates presented in the bottom panel are shown as $\mathrm{OH}$-equivalents, termed $\Sigma \mathrm{OH}_{\text {new }}$, and account for the conversion factors in the radical propagation steps, i.e., $\mathrm{RO}_{2} \rightarrow \mathrm{OH}$ and $\mathrm{HO}_{2} \rightarrow \mathrm{OH}$, as described in more detail in Part 2 (Sheehy et al., 2010). Figure 1 is accompanied by Table 1, which shows the percent contribution to $\Sigma \mathrm{OH}_{\text {new }}$ from various sources at selected times throughout the day, as well as day and nighttime averages. Pathways with an insignificant contribution are not shown.

The daytime $\Sigma \mathrm{OH}_{\text {new }}$ around noon is about 25 times larger than at night. A distinct diurnal pattern is observed. Radical production rates are high already shortly after sunrise $\left(2 \mathrm{ppb} \mathrm{h}^{-1}\right.$, or $1.1 \times 10^{7}$ molec $\mathrm{cm}^{-3} \mathrm{~s}^{-1}$ at 07:00 a.m.), predominantly due to the production of $\mathrm{OH}$ radicals. The production rates continue to rise and reach a plateau in the mid-morning $\left(13 \mathrm{ppbh}^{-1}\right.$, or $6.9 \times 10^{7}$ molec $\mathrm{cm}^{-3} \mathrm{~s}^{-1}$ at 10:00 a.m.). Sustained radical production persists at high level until about 12:30 p.m. and begins to decrease afterwards. A continuous decrease in radical production is observed during afternoon hours until about 06:00 p.m. $\left(1.0 \mathrm{ppbh}^{-1}\right.$, or $5.4 \times 10^{6}$ molec $\mathrm{cm}^{-3} \mathrm{~s}^{-1}$ at $06: 00$ p.m.). Radical production rates remain flat until the early morning hours. The decrease in $\mathrm{OH}, \mathrm{HO}_{2}$, and $\mathrm{RO}_{2}$ radical production rates during afternoon hours coincides with decreasing $\mathrm{O}_{3}$ concentrations due to pollution export from the MCMA, and reflects the strong coupling between the abundance of secondary pollutants and photochemical activity.

The 12-h daytime average $\Sigma \mathrm{OH}_{\text {new }}\left(6.5 \mathrm{ppbh}^{-1}\right.$, or $3.5 \times 10^{7}$ molec $\left.\mathrm{cm}^{-3} \mathrm{~s}^{-1}\right)$ is equally attributable to $\mathrm{OH}$ and $\mathrm{HO}_{2}$ sources (both about $40 \%$ ), while $\mathrm{RO}_{2}$ sources contribute about $20 \%$. The photolysis of secondary OVOC other than $\mathrm{HCHO}$ accounts for about $33 \%$ of $\Sigma \mathrm{OH}_{\text {new }} . \Sigma \mathrm{OH}_{\text {new }}$ from other OVOC is $60 \%$ due to new $\mathrm{HO}_{2}$ formation, and $40 \%$ due to new $\mathrm{RO}_{2}$ formation. $\mathrm{O}_{3}$ and $\mathrm{HCHO}$ are the most important single molecule radical sources in the MCMA, and are equally important $\left(20 \%\right.$ each). The $\mathrm{O}_{3} /$ alkene source adds nearly $15 \%$, with new $\mathrm{OH}-$ and $\mathrm{RO}_{2}$ production contributing about equal amounts. HONO contributes about $12 \%$ over this average period, and is more important in the morning. Our model estimates an average daytime $\mathrm{NO}_{3}$ radical concentration of about 0.6 pptv and about 1 pptv around noon. Daytime $\mathrm{NO}_{3}$ radical reactions make a very small contribution to daytime $\Sigma \mathrm{OH}_{\text {new }}$, reflecting high NO concentrations, and the fact that radical production rates from other sources are comparably large.

During the night, the $\Sigma \mathrm{OH}_{\text {new }}$ is determined from the reaction of alkenes with $\mathrm{O}_{3}$ and $\mathrm{NO}_{3}$. The 8-h nighttime average (08:00 p.m.-04:00 a.m.) $\Sigma \mathrm{OH}_{\text {new }}\left(0.48 \mathrm{ppbh}^{-1}\right.$, or $2.6 \times 10^{6}$ molec $\left.\mathrm{cm}^{-3} \mathrm{~s}^{-1}\right)$ is dominated by $\mathrm{O}_{3} /$ alkene reactions. The $\mathrm{OH}$ and $\mathrm{RO}_{2}$ sources contribute roughly similar amounts, and in sum account for about $80 \% \Sigma \mathrm{\Sigma OH}_{\text {new }}$; new $\mathrm{HO}_{2}$ accounts for a minor radical source at night. The only direct nighttime source of $\mathrm{OH}$ and $\mathrm{HO}_{2}$ radicals is the reaction between $\mathrm{O}_{3}$ and alkenes. On the other hand, for practical purposes the reactions of alkenes with $\mathrm{NO}_{3}$ exclusively generate new $\mathrm{RO}_{2}$ radicals. The model suggests that such $\mathrm{NO}_{3} /$ alkene reactions account for some $8-24 \%$ of nighttime $\Sigma \mathrm{OH}_{\text {new }}$; the remaining new radical production is from $\mathrm{O}_{3} /$ alkenes. If we force the scaled upper limit 8-h average $\mathrm{NO}_{3}$ radical concentration of $1.5 \mathrm{pptv}$ at night (about six times the predicted values), then the reaction between $\mathrm{NO}_{3}$ 
and alkenes could account on average for about half of nighttime $\Sigma \mathrm{OH}_{\text {new }}$. However, such scaled $\mathrm{NO}_{3}$ concentrations do not account for the rapid $\mathrm{NO}_{3}$ sink reaction with $\mathrm{NO}$ (see Sect. 3.3, and Fig. 3), and the actual $\Sigma \mathrm{OH}_{\text {new }}$ from $\mathrm{NO}_{3}$ at roof-top-level is likely much lower. In the near field chemical regime at roof-top-level, the $\mathrm{NO}_{3} /$ alkene source is a minor pathway for $\Sigma \mathrm{OH}_{\text {new }}$ at night.

\subsection{Production of $\mathrm{OH}, \mathrm{HO}_{2}$, and $\mathrm{RO}_{2}$ radicals}

\subsubsection{Sources for $\mathrm{OH}$ radicals}

The production of $\mathrm{OH}$ radicals from sources is high $\left(4 \mathrm{ppbh}^{-1}\right.$, or $2.1 \times 10^{7}$ molec $\mathrm{cm}^{-3} \mathrm{~s}^{-1}$ ) about two hours after sunrise, and near constant throughout the morning. It starts to decrease after noontime (12:00 p.m. CST), and is at least an order of magnitude lower at night. The predominant daytime $\mathrm{OH}$ radical sources are: (1) the photolysis of $\mathrm{HONO}$, (2) the photolysis of $\mathrm{O}_{3}$, and (3) the $\mathrm{O}_{3} /$ alkene reactions. In the early morning hours, the photolysis of HONO dominates the formation of $\mathrm{OH}$ radicals. As photochemical $\mathrm{O}_{3}$ accumulates, the photolysis of $\mathrm{O}_{3}$ becomes a dominant source of $\mathrm{OH}$ in the late morning and throughout most of the day, accounting for about $80 \%$ at peak ozone levels. It is noteworthy that small but "non-zero" $\mathrm{O}_{3}$ concentrations in the presence of high alkene concentrations during early hours, and unmeasured products from nighttime processing of VOCs present a significant source for $\mathrm{OH}$ radicals other than $\mathrm{HONO}$ in the early morning. Few ppb of $\mathrm{O}_{3}$ coexist with several $10 \mathrm{ppb}$ of NO shortly after sunrise, and contribute about $20 \%$ to $\mathrm{OH}$ production, illustrating how small changes in ozone may have a significant effect on $\mathrm{OH}$ radical production rates at this time of day. Difficulties with the exact quantification of low $\mathrm{O}_{3}$ levels exist for indirect techniques, which are widely used in current air quality monitoring networks (see discussion in Dunlea et al., 2006). An additional uncertainty exists in the speciation of alkenes, which can be affected during sample storage (Atkinson et al., 1984; Jenkin et al., 2005). OH production from $\mathrm{O}_{3}$ /alkenes is the only significant gas-phase non-photolytic source of $\mathrm{OH}$ during the day and at night.

\subsubsection{Sources for $\mathrm{HO}_{2}$ radicals}

The production of $\mathrm{HO}_{2}$ radicals is smaller than that of $\mathrm{OH}$ shortly after sunrise, and continuously increases to reach values around $5.8 \mathrm{ppbh}^{-1}$ (or $3.1 \times 10^{7} \mathrm{molec}^{-3} \mathrm{~s}^{-1}$ ) around noontime. As in the case of $\mathrm{OH}$, it starts to decrease after noon. New $\mathrm{HO}_{2}$ is only a significant radical source during the day; the new $\mathrm{HO}_{2}$ production is at least two orders of magnitude lower at night. The predominant daytime sources for $\mathrm{HO}_{2}$ are (1) the photolysis of $\mathrm{HCHO}$, and (2) the photolysis of other secondary OVOCs. HCHO photolysis accounts for more than half, the sum of other OVOCs for about $45 \%$ of the midday $\mathrm{HO}_{2}$ production. The photolysis of $\mathrm{CH}_{3} \mathrm{CHO}$ and $\mathrm{O}_{3}$ /alkene reactions contribute less than $2 \%$ new $\mathrm{HO}_{2}$ radicals throughout the day. During the night the only significant $\mathrm{HO}_{2}$ radical source is from $\mathrm{O}_{3} /$ alkene reactions.

\subsubsection{Sources for $\mathrm{RO}_{2}$ radicals}

The diurnal profile of $\mathrm{RO}_{2}$ radical production is qualitatively similar to that of $\mathrm{HO}_{2}$ radicals, though peak values around noontime are smaller $\left(3.8 \mathrm{ppbh}^{-1}\right.$, or $2.0 \times 10^{7}$ molec $\mathrm{cm}^{-3} \mathrm{~s}^{-1}$ at 10:00 a.m.). Also, the new $\mathrm{RO}_{2}$ production rate is about an order of magnitude lower at night, compared to peak daytime production. The predominant daytime sources for $\mathrm{RO}_{2}$ are the photolysis of secondary OVOCs, accounting for nearly $78 \%$ of new $\mathrm{RO}_{2}$ radical production at midday, and about $66 \%$ on a 12 -h daytime average basis. Some minor additional $\mathrm{RO}_{2}$ is produced from $\mathrm{O}_{3}$ /alkene reactions and reactions of $\mathrm{NO}_{3}$ with alkenes, phenol- and furanone-type products of the $\mathrm{OH}$-radical initiated oxidation of aromatic hydrocarbons. While these reactions only account for a minor source of $\mathrm{RO}_{2}$ radicals, they provide an interesting link between the $\mathrm{RO}_{\mathrm{x}}$ and $\mathrm{NO}_{\mathrm{x}}$ cycles (see Sect. 3.3).

\subsection{Direct observations of $\mathrm{NO}_{3}$ radicals}

$\mathrm{NO}_{3}$ radicals were detected during all nights that measurements were attempted. The spectral proof of the successful detection is presented in Fig. 2. The highest optical density of $\mathrm{NO}_{3}$ radical absorption was $9.6 \times 10^{-3}$, corresponding to a concentration of $(9.6 \pm 1.1) \times 10^{8}$ mole cm $^{-3}$ or $(50 \pm 6)$ pptv. The nighttime concentration-time profile varied between individual nights. Typically, detectable concentrations were observed during events that lasted $1-3 \mathrm{~h}$. The $\mathrm{NO}_{3}$ concentrations typically peaked around midnight $( \pm 2 \mathrm{~h})$, sometimes also later in the evening, and varied between 10 and 50 pptv. The nighttime average $\mathrm{NO}_{3}$ mixing ratio for all nights (19:00-04:00) is about 7 pptv (at DOAS\#2 heights). No $\mathrm{NO}_{3}$ was detected during the afternoon hours and the early evening prior to sunset, and concentrations were below the detection limit during early morning hours. To our knowledge this is the first direct detection of $\mathrm{NO}_{3}$ radicals in the urban core of a megacity.

Interestingly, our direct $\mathrm{NO}_{3}$ radical observations at a mean height of $70 \mathrm{~m}$ above ground pose an apparent conundrum to explain inferences of negligible $\mathrm{NO}_{3}$ chemistry at the CENICA roof-top level: An isomer-analysis of nitroPAH samples revealed a very minor contribution of $\mathrm{NO}_{3}$ radicals to PAH processing (Arey et al., 2004). It is noteworthy that negligible $\mathrm{NO}_{3}$ radical concentrations are predicted at rooflevel by MCM, and low $\mathrm{NO}_{3}$ at roof level is also expected based on our scaling procedure to account for vertical gradients (Sect. 2.2). However, nitro-PAHs are sufficiently long lived that they should be observable at roof level if indeed formed, and thus the absence of nitro-PAHs at roof level contains relevant (and potentially important) 
information about the processing of primary pollutants at night. Freshly emitted PAHs are collocated in plumes that contain elevated $\mathrm{NO}$, which rapidly destroys $\mathrm{NO}_{3}$ radicals: $\mathrm{NO}_{3}+\mathrm{NO} \rightarrow \mathrm{NO}_{2}$. This is corroborated in Fig. 3, where elevated $\mathrm{NO}_{3}$ concentrations tend to correlate with elevated $\mathrm{O}_{3}$, while air masses with higher $\mathrm{NO}_{2}\left(\right.$ lower $\left.\mathrm{O}_{3}\right)$ tend to contain virtually no $\mathrm{NO}_{3}$. We conclude that even though $\mathrm{NO}_{3}$ radical concentrations of $50 \mathrm{ppt}$ are observed, this should not be taken as evidence that primary pollutants, like PAHs, are easily processed by $\mathrm{NO}_{3}$ radicals at night.

\subsubsection{Does $\mathrm{NO}_{3}$ contribute to nighttime $\mathrm{OH}$ ?}

Nighttime $\mathrm{OH}$ radical concentrations are currently not well understood and subject to ongoing debate. As shown in Fig. 3, the nighttime $\mathrm{OH}$ concentration correlates better with $\mathrm{O}_{3}$ than with $\mathrm{NO}_{3}$ in the early evening. This is true also, though to a lesser extent, in the later night hours. However, a conclusion on whether $\mathrm{O}_{3}$ or $\mathrm{NO}_{3}$ control the nighttime $\mathrm{OH}$ concentration is complicated by the fact that both gases tend to be correlated. From the discussion presented in Sect. 3.1, it is likely that $\mathrm{NO}_{3}$ radicals make a minor and possibly significant contribution, to nighttime $\mathrm{OH}$ radical concentrations already in the near field chemical regime. The occurrence of $\mathrm{NO}_{3}$ concentrations in episodes, and the lack of co-located open-path $\mathrm{NO}$ data observed in the same air mass as $\mathrm{NO}_{3}$, makes it difficult to compare with a median model. Like NO, $\mathrm{NO}_{3}$ radicals facilitate the cycling of $\mathrm{RO}_{2}$ and $\mathrm{HO}_{2}$ into $\mathrm{OH}$. It is noteworthy that the propagation efficiency of $\mathrm{RO}_{2}$ into $\mathrm{OH}$ radicals is controlled by $\mathrm{NO}$ in our model; $\mathrm{NO}_{3}$ reactions are negligible in all cases studied. Different conditions are expected in the intermediate and far-field photochemical regime, i.e., $\mathrm{NO}_{3}$ enriched air masses at altitudes of several hundred meters above ground, and in the $\mathrm{O}_{3}$-rich city plume downwind of the MCMA. In similar air masses, $\mathrm{NO}_{3}$ concentrations of several hundred pptv have been observed (von Friedeburg et al., 2002; Brown et al., 2006). Under these conditions $\mathrm{NO}$ is very low; the efficiency of $\mathrm{RO}_{2}$ radicals to propagate into $\mathrm{OH}$ radicals $\left(\mathrm{RO}_{2}+\mathrm{NO}_{3} \rightarrow \mathrm{RO}+\right.$ products; $\mathrm{RO}+\mathrm{O}_{2} \rightarrow \mathrm{HO}_{2}$-products; $\mathrm{HO}_{2}+\mathrm{NO}_{3} \rightarrow \mathrm{OH}+$ products) conversions is controlled by $\mathrm{NO}_{3}$ reactions, which proceed more than an order of magnitude slower than the analogous reaction involving $\mathrm{NO} ; \mathrm{NO}_{3}$ competes with peroxy-radical self reactions which can terminate the radical chain. The efficiency for $\mathrm{RO}_{2} \rightarrow \mathrm{OH}$ conversion is thus lower than in a high NO scenario such as ours. A possible exception could arise from recent findings that peroxy-radical self reactions propagate the radical chain (Hasson et al., 2004; M. E. Jenkin, personal communication, 2006). If these reactions were confirmed as a more general pathway, $\mathrm{NO}_{3}$ reactions would gain importance as a source for nighttime $\mathrm{OH}$-radical in the intermediate and far-field chemical regime downwind of large urban centers. Our model indicates that $\mathrm{NO}_{3}$ does not contribute much to nighttime $\mathrm{OH}$ production at roof level during MCMA-2003.

\subsubsection{Processing of furanones by daytime $\mathrm{NO}_{3}$}

We did not find evidence of $\mathrm{NO}_{3}$ radicals accumulating to measurable concentrations during the day in Mexico City. This is in contrast to Houston (Geyer et al., 2003), and New England (Brown et al., 2005), where daytime $\mathrm{NO}_{3}$ concentrations have been observed, and form a non-negligible process for the oxidation of highly reactive VOC. This difference is the result of lower $\mathrm{O}_{3}$ during afternoons, and likely also significant $\mathrm{NO}_{3}$ sink reactions in Mexico City. In contrast to Houston, biogenic VOC concentrations are much lower in Mexico City (quantified as $<5 \%$ of $\mathrm{OH}$-reactivity during MCMA-2003 in Volkamer et al., 2006).

However, the daytime $\mathrm{NO}_{3}$ radical concentration is on the order of $0.5-1 \mathrm{ppt}$ in our model. $\mathrm{NO}_{3}$ reactions with anthropogenic alkenes, phenol-type and furanone-type products from aromatic hydrocarbon oxidation contribute about $26 \%, 36 \%$, and $15 \%$ of the daytime $\mathrm{RO}_{2}$ sources from $\mathrm{NO}_{3}-$ reactions, respectively. These reactions account in sum for about $7 \%$ of the daytime $\mathrm{NO}_{3}$-sink reactions, and thus can compete with rapid $\mathrm{NO}_{3}$ photolysis and $\mathrm{NO}$ reactions for $\mathrm{NO}_{3}$ radicals. The $\mathrm{NO}_{3}$ production rate at $100 \mathrm{ppb}_{3}$ and $10 \mathrm{ppb} \mathrm{NO}_{2}$ is about $1.3 \times 10^{7}$ molec $\mathrm{cm}^{-3}$, and the overall flux through $\mathrm{NO}_{3}+\mathrm{VOC}$ reactions is ca. $10^{6}$ molec $\mathrm{cm}^{-3} \mathrm{~s}^{-1}$. Daytime $\mathrm{NO}_{3}$-reactions with furanones account for some 5$15 \%$ of the furanone lifetime in our model. The relevance of daytime $\mathrm{NO}_{3}$-reactions, previously noted only for phenols (Kurtenbach et al., 2002), is highlighted here also for furanone-type compounds.

\subsection{3 $\quad \mathrm{N}_{2} \mathrm{O}_{5}$ uptake to aerosol: a likely source for nitryl chloride in the MCMA}

$\mathrm{O}_{\mathrm{x}}$ (sum of $\mathrm{NO}_{2}$ and $\mathrm{O}_{3}$ ) is found to decrease at a rate of $2.1 \mathrm{ppb} \mathrm{h}^{-1}$ at night, see Fig. 3. This loss of $\mathrm{O}_{\mathrm{x}}$ is attributed to the combination of various factors: (1) $\mathrm{O}_{\mathrm{x}}$ to $\mathrm{NO}_{\mathrm{y}}$ conversion processes, such as $\mathrm{N}_{2} \mathrm{O}_{5}$ hydrolysis on aerosols and ground surfaces, (2) dry deposition of $\mathrm{O}_{\mathrm{x}}$ or $\mathrm{NO}_{\mathrm{y}}$, and possibly also (3) pollution export from the MCMA.

The heterogeneous uptake of $\mathrm{N}_{2} \mathrm{O}_{5}$ can trigger reactions with $\mathrm{Cl}^{-}$that can lead to the formation of nitryl chloride $\left(\mathrm{ClNO}_{2}\right)$ (Finlaysson Pitts et al., 1989), and molecular chlorine $\left(\mathrm{Cl}_{2}\right)$ (Roberts et al., 2008). This reaction is accelerated under acidic conditions, which are typical for particles in Mexico City (e.g., pH 4, Volkamer et al., 2007). We note that aerosols were mostly aqueous during MCMA-2003, and contained non-negligible amounts of chloride (San Martini et al., 2006). Assuming an $\mathrm{N}_{2} \mathrm{O}_{5}$ concentration of $0.2 \mathrm{ppb}$, an $\mathrm{N}_{2} \mathrm{O}_{5}$ uptake coefficient $\gamma=0.01$ (compare e.g., Brown et al., 2006), and a typical condensable sink aerosol surface area $S=400 \mathrm{~mm}^{2} \mathrm{~m}^{-3}$ (compare Fig. 1 in Volkamer et al., 2007, at night), the heterogeneous $\mathrm{N}_{2} \mathrm{O}_{5}$ uptake to aerosols can account for about 3 ppb $\mathrm{N}_{2} \mathrm{O}_{5}$ loss over $12 \mathrm{~h}$. $\mathrm{Cl}^{-}$concentrations often are above $0.1 \mathrm{M}$ in Mexico City aerosols (San Martini et al., 2006), and under those conditions $\mathrm{N}_{2} \mathrm{O}_{5}$ 
is efficiently converted into $\mathrm{ClNO}_{2}$ (Behnke et al., 1997; Roberts et al., 2008). Based on this rough estimate we attribute a significant, though likely not major portion of the observed $\mathrm{O}_{\mathrm{x}}$ losses (on the order of $10 \%$, or $2-3 \mathrm{ppb}$ ) to the formation of $\mathrm{ClNO}_{2}$.

\subsection{Source and sink considerations of HONO}

HONO is heterogeneously formed at night, and is an important radical source in the early morning (Platt et al., 1980), yet our understanding of the HONO sources remains incomplete. The constrained MCM model is found to predict HONO surprisingly well. The measured HONO profiles from DOAS\#1 and DOAS\#2 are compared with HONO predictions in Fig. 4. Regardless of the meteorological conditions, PSS-HONO accounts for at least half of the HONO concentrations at 07:00 a.m., and virtually all HONO at 09:00 a.m. Figure 4 demonstrates that a small $\mathrm{OH}$ concentration in the presence of high morning NO concentrations account for ppbv-levels of HONO at 08:00 a.m. Few previous studies had simultaneous and collocated $\mathrm{OH}, \mathrm{NO}$, $\mathrm{HONO}$ and $J_{\mathrm{HONO}}$ measurements available; the interpretation of most HONO as being a radical reservoir is fully consistent with the error bars presented in Fig. 3 of Martinez et al. (2003). Additional HONO formation from dark sources, like the heterogeneous $\mathrm{NO}_{2}$ conversion on urban surfaces (see, e.g., Arens et al., 2001; Ramazan et al., 2006 and references therein) do appear to contribute significant amounts of HONO only before 08:00 a.m. Thereafter PSSHONO (and a minor contribution from dark HONO sources) account for essentially all of the observed HONO. Around solar noon the PSS and dark sources can account for some $(35 \pm 15)$ pptv; these model results are robust for different meteorological conditions and independent of relative humidity. This is of the same order of magnitude as the upper limit HONO concentration that can be inferred from the DOAS\#2 detection limit. Statistical averaging of DOAS\#2 data yields (58 \pm 76$)$ pptv and (21 \pm 76$)$ pptv HONO on a campaign average and median basis; error bars correspond to one-sigma standard-deviation among individual days around solar noon. An independent quantification of daytime HONO concentrations in Mexico City remains desirable. However, it is noteworthy that photo-induced processes (included in "dark+other" HONO sources in Table 1) appear to contribute - if any - only very minor amounts to ambient HONO concentrations in Mexico City. For example, a photochemical HONO source of $5 \times 10^{10}$ molec $\mathrm{cm}^{-2} \mathrm{~s}^{-1}$ from the ground (Stemmler et al., 2006), diluted in a PBL of $3 \mathrm{~km}$ height (typical for Mexico City), corresponds to a HONO mixing ratio of only 4.3 pptv around noon.

The characterization of daytime HONO sources in the urban atmosphere - if attempted in the future - suffers from the need to subtract a large steady-state HONO concentration. This steady-state HONO can only be quantified at the precision with which the reaction rate constant of $\mathrm{OH}$ with
NO is known, i.e., 20\% (Sander et al., 2006); in our estimate the largest uncertainty is the absolute uncertainty in $\mathrm{OH}$ measurements. For example, in order to quantify a photo-induced HONO concentration of 25 pptv on top of a 25 pptv PSSHONO background with $25 \%$ uncertainty, the absolute precision of $\mathrm{OH}$ measurements needs to be $15 \%$ or better; such measurements are currently very difficult to achieve. High precision measurements of HONO (Kleffmann et al., 2006), $\mathrm{NO}$, and $J_{\mathrm{HONO}}$ are necessary - though unlikely to be limiting - for efforts to quantify excess HONO over PSS-HONO in the urban atmosphere.

\section{Faster than expected HONO photolysis?}

We observe a significant delay in the decrease of HONO in the model if $J_{\mathrm{HONO}}$ is based on the value listed in Sander et al. (2006). Notably, by 09:00 a.m. the contribution of dark HONO sources makes a very small contribution $(<10 \%$, see Table 1), and HONO concentrations between two DOAS instruments agree well. This indicates that uncertain scaling of dark HONO sources and vertical gradients do not appear to limit our measurement-model comparison at 09:00 a.m. The difference between measured and modeled HONO concentrations persists for several hours in the morning (see inset of Fig. 4) until HONO concentrations fall to values close to the detection limit. Model predicted HONO exceeds the observations by about 70\% at 09:00 a.m., when uncertainty in PSS-HONO production rate is on the order of $\sim 40 \%$ and uncertainty in the HONO measurements by DOAS\#2 is $\sim 35 \%$. Model predicted HONO and observed HONO are only marginally in agreement. The over-prediction of HONO in the model indicates that a HONO sink is missing in the model. By scaling our $J_{\mathrm{HONO}}$ by 1.43 we observe good agreement between the model and measurements throughout the day (see Fig. 4, lower panels); scaling by 1.22 brings the predicted HONO into marginal agreement with DOAS\#2 error bars.

Recent direct measurements of $J_{\mathrm{HONO}}$ reported values that were about 1.28 times higher than expected (Wall et al., 2006). Uncertainties in the absolute values of the HONO absorption cross-section arise from necessary "offset" corrections due to lamp drifts in the currently recommended HONO cross section (Stutz et al., 2000; Sander et al., 2006), which can account for about 1.13 to 1.2 times faster HONO photolysis (Stutz et al., 2000; Bongartz et al., 1991). In principle $\mathrm{OH}$ overtone pumping by visible and infrared photons can also lead to additional HONO photolysis from the electronic ground state (Donaldson et al., 1997). This process is more important at higher altitudes (Witonsky et al., 2001), but could make a minor contribution at the altitudes of Mexico City. We find independent evidence for fasterthan-expected HONO photolysis that - within error bars can probably be rationalized from uncertainties in the UV spectral range. A reduction in the offset uncertainty in the currently recommended UV spectrum remains desirable. 


\subsection{Source apportionment of $\mathrm{HCHO}$}

The observed formaldehyde concentrations in the MCMA are a result of emissions, photochemistry, and an unknown background source, which is generally small (1-2 ppb) and appears to be related to a VOC chemical source (Garcia et al., 2006). The atmospheric lifetime of HCHO in the MCMA is on the order of $1-2 \mathrm{~h}$; sustained and elevated concentrations of HCHO in the MCMA are thus an indicator that $\mathrm{HCHO}$ is constantly formed from these sources throughout the day. Garcia et al. (2006) demonstrated that on a 24-h average basis, up to $70 \%$ of observed HCHO in the MCMA is photochemically produced. Measured ambient $\mathrm{HCHO}$, and the portion from photochemical and background sources are compared with the MCM predictions in Fig. 5. The lower limit nighttime $\mathrm{OH}$ concentration leads to accumulation of several ppb of HCHO (not shown), consistent with the interpretation of "background $\mathrm{HCHO}$ " from a chemical source (Garcia et al., 2006). Directly emitted HCHO is more relevant during morning hours, and photochemical sources are the most significant about $2 \mathrm{~h}$ after sunrise. Direct $\mathrm{HCHO}$ emissions are important to help jump start photochemistry (Lei et al., 2009), but become less important to sustain ozone and SOA formation in the mid-morning and later when photochemical sources of $\mathrm{HCHO}$ dominate.

MCM was used to characterize photochemical $\mathrm{HCHO}$ production in terms of: (1) the relative contribution of HCHO sources by VOC class (i.e., alkanes, alkenes, aromatics, OVOCs); (2) the relative contribution of oxidants, i.e., $\mathrm{OH}$, $\mathrm{O}_{3}$, and $\mathrm{NO}_{3}$; and (3) the portion of $\mathrm{HCHO}$ formed as a first vs. second (and higher) generation oxidation product. The results of the HCHO source apportionment modeling are shown in Fig. 6. On a daily average basis, we find that an overwhelming majority of the photochemical HCHO production proceeds from reactions that yield $\mathrm{HCHO}$ as a first generation oxidation product. The oxidation of alkenes is the major VOC precursor, and $\mathrm{OH}$ is the predominant oxidant that leads to the formation of photochemical HCHO in the MCMA. The $\mathrm{O}_{3} /$ alkene source, while significant, only accounts for some $17 \%$ of the photochemical HCHO production. The aromatic species make a smaller contribution, and are largely responsible for secondary $\mathrm{HCHO}$ production. $\mathrm{NO}_{3}$ radical initiated oxidation of VOCs and photolysis reactions are insignificant compared to other sources of $\mathrm{HCHO}$ in the MCMA.

\subsection{Comparison of Mexico City with other case studies}

Detailed studies for radical production are available for comparison from Los Angeles (Griffin et al., 2004), Nashville (Martinez et al., 2003), Pabsthum downwind of Berlin (Alicke et al., 2003), New York City (NYC; Ren et al., 2003), Milan (Alicke et al., 2002), Birmingham (Emmerson et al., 2005), Chelmsford downwind of London (Emmerson et al., 2007), rural environments (Zhou et al., 2002; Kleffmann et

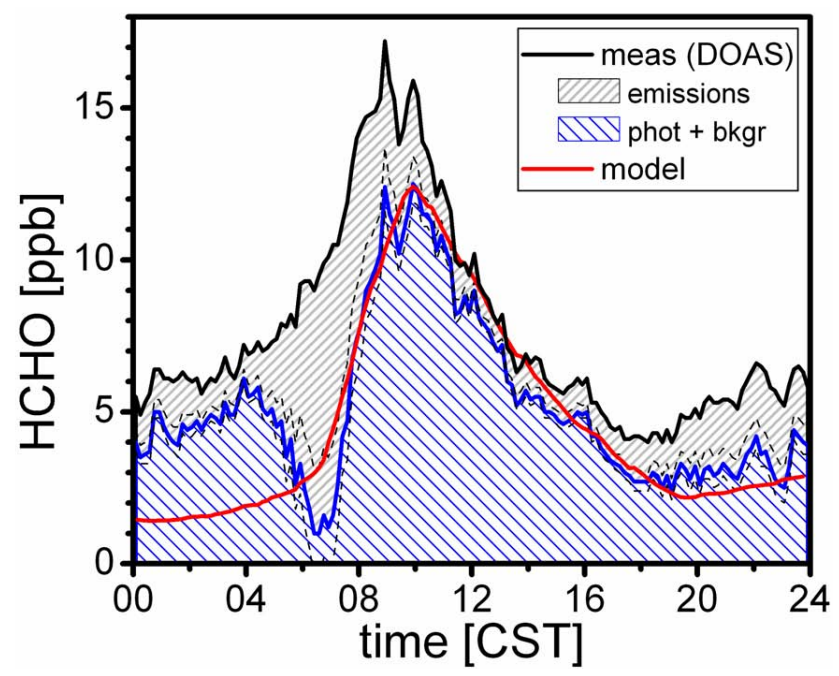

Fig. 5. HCHO observations (black line) are compared to the portion of $\mathrm{HCHO}$ produced from photochemical sources and background sources (blue line, shaded blue area), and from emissions (shaded gray area); the dotted lines represent the upper and lower limits of subtracting out emissions sources according to the procedure described by Garcia et al. (2006). Modeled HCHO concentrations (red line) are shown in which dilution was adjusted to match the blue line (after 10:00 a.m., see Sect. 2.2).

al., 2005; Acker et al., 2006) and the free troposphere (Singh et al., 1995; Arnold et al., 2004).

\subsubsection{Timing of radical production}

It is generally expected that the radical production rate during summer follows the abundance of sunlight and peaks around the time of lowest solar zenith angle (solar noon). Such correlations are indeed observed in NYC, Nashville, rural environments and also during cleaner days in Pabsthum and Milan, while peak radical production is shifted towards early afternoon hours in Los Angeles. There is only limited information given about the timing of radical production in Birmingham and Chelmsford, though the choice of averaging times in the presentation of the results from those studies (11:00 a.m.-03:00 p.m., centered around solar noon), and the relative importance of photolytic sources may be indicative of such correlation during summertime. Alternatively, a radical pulse from HONO in the early morning, decreasing radical production rate in the mid-morning, followed by a local maximum radical production rate around solar noon have been observed during individual days in Milan and Pabsthum.

In Mexico City, we did not observe a symmetric radical production rate around solar noon; neither did we observe a dip in mid-morning. Rather, the peak of new radical production is systematically shifted towards mid-morning, i.e., around 10:00 a.m. or three hours before solar noon (see Fig. 1). It is sustained at this high level until pollution is 
efficiently exported from the MCMA. The absence of both a morning peak and a mid-morning dip in the radical production rate is attributed to the particularly high rate from secondary sources (all formed as a result of photochemical processing of pollutants): photolysis of $\mathrm{HCHO}, \mathrm{O}_{3}$, and other OVOCs in sum contribute about $75 \%$ of the radical production rate around 11:00 a.m., and 85\% around 01:00 p.m. In other words, whatever radical source starts the processing of pollutants gets amplified by further radical production from secondary pollutants; the surrounding mountains trap secondary pollutants within the basin during mid-morning. Results from the MILAGRO/MCMA-2006 campaign (Dusanter et al., 2009; Molina et al., 2010) are generally consistent with our earlier findings. Our analysis highlights two phenomena: (1) the importance of radical sources that start the photochemical processing in the early morning; and (2) the non-linear feedbacks between meteorology (i.e., pollution export) and photochemical activity in the MCMA. These feedbacks have not been previously quantified at the radical level (i.e., radical production rates).

\subsubsection{Absolute radical source strength}

The overall radical production rate during MCMA-2003, as well as during the MILAGRO/MCMA-2006 field campaign (Dusanter et al., 2009) tends to be higher than in other urban environments, and on a routine basis is comparable to that found during a photochemical smog episode in Los Angeles in 1993 (Griffin et al., 2004). The radical production rate averaged over a 4-h time window centred near its peak is about 1.7 times higher than in Milan, 2 times that observed in Birmingham during summertime, 2.7 times that in Chelmsford, and 3 times higher than in Birmingham during wintertime. It is 3.3 times higher than in NYC and Nashville, 3.5 times higher than in Pabsthum, and 7-10 times than in rural environments. This comparison highlights the unique chemical activity of the Mexico City atmosphere.

Furthermore, the 24-h average $\mathrm{HO}_{\mathrm{x}}$ radical production rate in the upper troposphere $-2.3 \times 10^{4}$ molec $\mathrm{cm}^{-3} \mathrm{~s}^{-1}$ (Singh et al., 1995; Arnold et al., 2004) - is two to three orders of magnitude lower than in the MCMA. Recently, higher than expected concentrations of oxygenated hydrocarbons have been measured in the free troposphere (Kwan et al., 2006). Interestingly, new $\mathrm{HO}_{x}$ production rates from $\mathrm{CH}_{3} \mathrm{CHO}$ and $\mathrm{CH}_{3} \mathrm{COCH}_{3}$ in Mexico City are comparable to those in the free troposphere, about $5 \times 10^{5}$ and $10^{4} \mathrm{molec} \mathrm{cm}^{-3} \mathrm{~s}^{-1}$ respectively $(11 \mathrm{~km}$ height, solar zenith angle $\mathrm{SZA}=15$ degrees, $\left.\left[\mathrm{CH}_{3} \mathrm{CHO}\right]=200 \mathrm{pptv},\left[\mathrm{CH}_{3} \mathrm{COCH}_{3}\right]=500 \mathrm{pptv}\right)$. While $\mathrm{O}_{3}$ or HCHO photolysis are important radical sources in both of these very different compartments of the atmosphere, the higher-than-expected concentrations of $\mathrm{CH}_{3} \mathrm{CHO}$ in the free troposphere coupled with faster photolysis at higher altitude lead to $\mathrm{HO}_{\mathrm{x}}$ production rates that compare or even exceed that from $\mathrm{O}_{3}$ or $\mathrm{HCHO}$ photolysis, emphasizing the role of other radical sources than ozone at high altitude (Frost et al.,
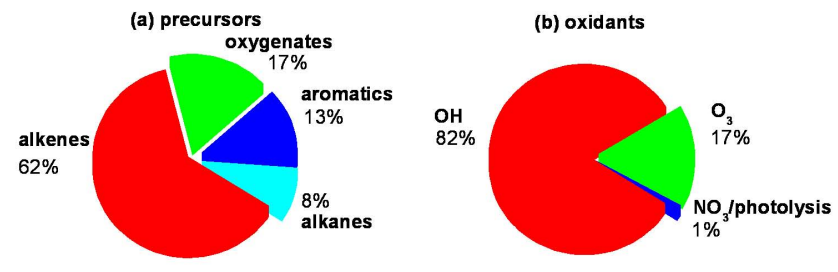

(c) product generation

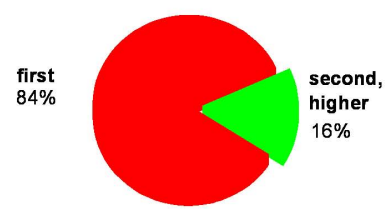

Fig. 6. Source apportionment of photochemical HCHO production. (a) The precursors of HCHO are separated by VOC class. (b) The effect of different oxidants is assessed. (c) The time scale of HCHO production is assessed in terms of oxidation step. An overwhelming majority of $\mathrm{HCHO}$ is formed as a first generation oxidation product from VOC oxidation; $\mathrm{HCHO}$ formation as second- and higher generation oxidation products makes only a minor contribution.

1999). The relevance of the polluted urban atmosphere as a source for oxidized hydrocarbons is expected to increase in the future.

\subsubsection{Relative importance of different radical sources}

The average daytime contribution to radical production rates from different sources in the MCMA is compared to other urban influenced environments in Table 2. While OVOC appear to be the most important radical source, the relative importance of other sources is fairly homogeneous (see also Table 1, and Sects. 3.1 and 3.7). This is different from previously studied atmospheres, in which typically one radical source dominates: $\mathrm{HONO}$ in NYC; $\mathrm{HCHO}$ in Milan; $\mathrm{O}_{3}$ in the South Coast Air Basin in California (2010 scenario), and in Nashville, $\mathrm{O}_{3}$ /alkene reactions in Birmingham during wintertime, secondary OVOC in the South Coast Air Basin (1993 scenario), and in Birmingham and Chelmsford during summertime. Downwind of Berlin, in Pabsthum, $\mathrm{O}_{3}$ and $\mathrm{HCHO}$ photolysis are both particularly important. Despite the considerable variability among different urban polluted, and between urban and rural atmospheres, some generalizations can be drawn.

\section{HONO photolysis}

We have included HONO among the radical sources in Tables 1 and 2, neglecting the fact that throughout most of the day a significant portion of HONO appears to be a radical reservoir instead of a radical source in the MCMA. At 09:00 a.m. virtually all HONO is accounted as PSS-HONO; dark HONO sources do not contribute significantly to the HONO production rate at that time. In the later morning and 
Table 2. Comparison of the relative importance of radical sources in Mexico City with other urban and rural atmospheres (daytime average $\mathrm{HO}_{\mathrm{x}}$ radical production rates).

\begin{tabular}{lrrrrrl}
\hline & $\begin{array}{r}\mathrm{HCHO} \\
\text { Phot. }\end{array}$ & $\begin{array}{r}\mathrm{HONO} \\
\text { Phot. }\end{array}$ & $\begin{array}{r}\mathrm{O}_{3} \\
\text { Phot. }\end{array}$ & $\begin{array}{r}\mathrm{O}_{3} / \\
\text { alkenes }\end{array}$ & others & References \\
\hline Rural boundary layer & & & & & & \\
Pinnacle State Park, NY, USA & 14 & 18 & 44 & n.n. & $25^{\mathrm{a}}$ & (Zhou et al., 2002) \\
Forest near Julich, GER & 25 & 27 & 23 & 6 & $20^{\mathrm{a}}$ & (Kleffmann et al., 2005) \\
Hohenpreissenberg, GER & 14 & 32 & 30 & n.n. & $25^{\mathrm{a}}$ & (Acker et al., 2006) \\
Urban boundary layer & & & & & & \\
California South Coast Air Basin, USA: & & & & & & (Griffin et al., 2004) \\
Central Los Angeles - 1993 & 21 & 11 & 31 & 6 & $31^{\mathrm{e}}$ & \\
Central Los Angeles - 2010 & 13 & 8 & 49 & 2 & $28^{\mathrm{e}}$ & \\
Azousa - 1993 & 17 & 6 & 28 & 6 & $43^{\mathrm{e}}$ & \\
Azousa - 2010 & 12 & 4 & 47 & 3 & $34^{\mathrm{e}}$ & \\
Riverside - 1993 & 14 & 4 & 32 & 3 & $47^{\mathrm{e}}$ & \\
Riverside - 2010 & 11 & 4 & 46 & 2 & $37^{\mathrm{e}}$ & \\
Milan, Italy & 34 & 16 & 20 & 8 & $20^{\mathrm{a}}$ & (Alicke et al., 2002) \\
Nashville, TN, USA & 29 & 8 & 47 & 0.2 & $20^{\mathrm{a}}$ & (Martinez et al., 2003) \\
Pabstum (near Berlin), GER & 37 & 17 & 39 & 6 & $2^{\mathrm{b}}$ & (Alicke et al., 2003) \\
New York City, NY, USA & 8 & 56 & 13 & 10 & $13^{\mathrm{c}}$ & (Ren et al., 2003) \\
Birmingham, UK (summer) & 8 & 7 & 6 & 25 & $54^{\mathrm{d}}$ & (Emmerson et al., 2005) \\
Birmingham, UK (winter) & 1 & 15 & 0.5 & 59 & $26^{\mathrm{d}}$ & \\
Chelmsford (near London), UK & 6 & 10 & 14 & 20 & $50^{\mathrm{d}}$ & (Emmerson et al., 2007) \\
Mexico City, MEX - 2006 & 24 & 34 & 6 & 19 & $17^{\mathrm{c}}$ & (Dusanter et al., 2009) \\
Mexico City, MEX - 2003 & 19 & 12 & 19 & 12 & $38^{\mathrm{d}}$ & This work \\
\hline
\end{tabular}

a no number; value assumed for normalization and comparison purposes;

b only selected carbonyls measured; lower limit number;

c estimated using RACM;

$\mathrm{d}$ estimated using MCMv3.1 (mostly photolysis of OVOC);

$\mathrm{e}$ estimated using CIT air quality model (mostly photolysis of OVOC).

afternoon, the contribution from $\mathrm{HONO}$ to the overall radical production was low during MCMA-2003. Different results were obtained for HONO during the MILAGRO/MCMA2006 field campaign, where in another part of town HONO was found to be tendentially higher, and much higher in episodes (Dusanter et al., 2009). During some episodes daytime HONO was significant, and during those episodes the contribution from daytime HONO can have a significant impact on the overall radical production (Li et al., 2010). However, results from MCMA-2003 and MILAGRO/MCMA2006 show consistently that daytime HONO is not a routine occurrence in the MCMA, and the cause and frequency at which daytime HONO episodes occur are currently not well established.

Recently, significant daytime HONO concentrations in rural and forested environments indicate the presence of additional daytime HONO sources that are up to 64 times greater than the night time sources, and comparable to other sources like $\mathrm{HCHO}$ and $\mathrm{O}_{3}$-photolysis (Zhou et al., 2002; Kleffmann et al., 2005; Acker et al., 2006). The only laboratory study that could thus far present convincing evidence for atmospheric relevance is that by Stemmler et al. (2006). This photo-induced HONO source strength contributes about $0.3 \%$ to the $\Sigma \mathrm{OH}_{\text {new }}$ sources in the MCMA. Even a ten-fold increase in surface area (which in Mexico City is mostly due to abundant aerosol surface area, and only to a lesser extent due to vertical building surfaces) would make an insignificant contribution $(\sim 3 \%)$ to the overall noontime radical production rate here. Our observations are incompatible with findings in NYC (Ren et al., 2003), where HONO measurements with a wet-chemical technique (scrubbed derivatization HPLC) suggest high noontime radical production rates (about $10^{7}$ molec $\mathrm{cm}^{-3} \mathrm{~s}^{-1}$, or ten times the likely estimate, and twice the upper limit set by our measurements) corresponding to about $300 \mathrm{pptv}$ of HONO. These high daytime HONO concentrations are directly observable with currently available spectroscopic techniques; they certainly should have been observable with our instruments, and were observed during certain episodes with similar instruments during the MILAGRO field campaign. Strong differences in the relative importance of $\mathrm{HONO}$ as a radical source seem to exist in different polluted urban environments even within a 
city. Between NYC and the MCMA, differences exist in the types of available surface areas, the availability of sunlight in street-canyons, the vertical mixing-height and horizontal dispersion of pollutants. A direct confirmation of the HONO levels in NYC remains desirable. It is further noteworthy that our study identifies that secondary OVOC contribute about equal to radical production than HONO already shortly after sunrise.

\section{HCHO-photolysis}

The contribution from this source is highly variable. Compared to other urban environments, it is lower in the MCMA than downwind of Milan, Berlin and Nashville, but higher than in NYC, Birmingham and downwind of London. $\mathrm{HCHO}$ is an important radical source in the MCMA. About $70 \%$ of the average daytime radical production rate from $\mathrm{HCHO}$ is attributed to $\mathrm{HCHO}$ that forms from secondary sources (hydrocarbon photochemistry) (Garcia et al., 2006; Lei et al., 2009).

$\mathrm{HCHO}$ is emitted in significant amounts as part of vehicle exhaust in the MCMA (Zavala et al., 2006; Garcia et al., 2006). Conversely, targeted reductions of primary $\mathrm{HCHO}$ sources present an opportunity to slow down the rate of hydrocarbon oxidation. While primary $\mathrm{HCHO}$ only accounts for about $30 \%$ of the average daytime radical production rate from $\mathrm{HCHO}$-photolysis, the contribution peaks at around 09:00 a.m., when the net-radical production rate from other sources is either no longer $(\mathrm{HONO})$, or not yet $\left(\mathrm{O}_{3}\right)$ efficient. Primary HCHO sources contribute about $10 \%$ of the overall net-production of radicals before 10:00 a.m., and contribute significantly to the formation of those secondary species which sustain the exceptionally high $\Sigma \mathrm{OH}_{\text {new }}$ in the mid-morning. Reductions in primary $\mathrm{HCHO}$ sources can thus be expected to yield additional benefits from reducing the production rate of secondary species. Such amplification of benefits may however be out-weighed by parameters such as cycling chain length (Sheehy et al., 2010), which is highest in the early morning hours and decreasing towards the midmorning, when primary $\mathrm{HCHO}$ contributes most to $\Sigma \mathrm{OH}_{\text {new }}$. From a radical source perspective, the potential benefits of targeted primary $\mathrm{HCHO}$ reductions to reduce peak concentrations of secondary species like $\mathrm{O}_{3}$ and SOA warrant future investigation. It is important that future research on this subject includes the development of models that adequately represent radical sources other than $\mathrm{HCHO}$.

\section{O3-photolysis $_{3}$}

The contribution from this source exceeds $30 \%$ only in semipolluted and rural environments; it is generally below or close to $20 \%$ in more polluted environments, like Milan, NYC, and - interestingly - the MCMA. Despite frequent $\mathrm{O}_{3}$ concentrations that exceed $100 \mathrm{ppbv}$ in the MCMA, its $2220 \mathrm{~m}$ elevation above sea level, and tropical latitude, the daily average contribution from $\mathrm{O}_{3}$ photolysis is not higher than that observed in other polluted atmospheres. This reflects efficient venting of the MCMA during afternoons (de Foy et al., 2006), and the abundance of other radical sources. The moderate contribution from $\mathrm{O}_{3}$ photolysis in the urban atmosphere also means that any correlation of $\mathrm{OH}$ radical concentrations with $J_{\mathrm{O}_{3}}$ is rather a reflection of the fact that $85 \%$ of radical production is light-induced. Any such correlation should not be mistaken as evidence that $\mathrm{O}_{3}$ indeed controls $\mathrm{OH}$ radical concentrations in the urban atmosphere.

\section{$\mathrm{O}_{3} /$ alkene reactions}

A markedly different contribution from $\mathrm{O}_{3} /$ alkene sources is observed compared to previous studies. Alkenes directly contribute to $\Sigma \mathrm{OH}_{\text {new }}$ by reacting with ozone. They contribute further indirectly to $\Sigma \mathrm{OH}_{\text {new }}$ as the oxidation of alkenes by $\mathrm{OH}$ as the predominant source for photochemical HCHO in Mexico City (see Sect. 3.5); photochemical sources are also the predominant source of ambient $\mathrm{HCHO}$ during the day (Garcia et al., 2006). In addition, $\mathrm{O}_{3} /$ alkene reactions essentially can explain most of the $\mathrm{OH}$ radical observations at night (see Fig. 3 in Sheehy et al., 2010), leading to the nighttime accumulation of secondary pollutants that produce radicals from secondary OVOC photolysis in the early morning hours. Further, the storage of nighttime $\mathrm{OH}$-radicals in the form of PSS-HONO makes an important contribution to morning HONO levels. Photolysis of PSS$\mathrm{HONO}$, other OVOC and $\mathrm{O}_{3} /$ alkene reactions in sum are responsible for about $75 \%$ of the radical production rate one hour after sunrise. Notably, the three studies that employed a detailed chemical mechanism to study radical sources (Emmerson et al., 2005, 2007; this work) yield the highest estimates for the contribution from $\mathrm{O}_{3} /$ alkene reactions; lumped chemical codes seem to give lower estimates of $\mathrm{O}_{3} /$ alkene sources (see Table 2). $\mathrm{O}_{3}$ /alkene reactions make an important radical source during winter in Birmingham (Emmerson et al., 2005). The combined radical production rate attributable to alkene reactions exceeds that from any other source in the early morning in Mexico City. Notably, in the MCMA, the sum of the direct and indirect contributions of $\mathrm{O}_{3} /$ alkene reactions to $\Sigma \mathrm{OH}_{\text {new }}$ (on average about 30\%) is at least five times higher compared to the relative abundance of alkenes on a ppbC basis (i.e., 3-6\% ppbC at CENICA; see Velasco et al., 2007).

\section{Photolysis of secondary OVOC}

Most studies do not account for the radical production from the photolysis of OVOC other than HCHO. We find that OVOC photolysis other than HCHO accounts for $27 \%$ of the radical production about $1 \mathrm{~h}$ after sunrise, and this fraction increases to about $35 \%$ by 11:00 a.m. OVOC other than HCHO contribute about one third to the 12-h average daytime radical production rate during MCMA-2003. 
The summed radical production of several hundred OVOC species is larger than the radical production from HCHO. There are only three other studies available that assessed the relative importance of OVOC; two used a similar approach to the work presented here (Emmerson et al., 2005, 2007), and another used a 3-dimensional chemical transport model (Griffin et al., 2004). These studies also found a large contribution of OVOC, independent of the season. It should be noted that previous 1-dimensional box-model studies did not take active precautions to account for the accumulation of secondary pollutants (N. Carslaw, personal communication, 2007), and allowed OVOC concentrations to reach a balance between photochemical production and sink reactions (quasi steady-state). If pollution export from the MCMA was neglected in our study, about 2-3 times higher contribution from OVOC is predicted by our model. However, our study shows that OVOC make a significant contribution also if dilution is taken into account. We conclude that OVOC are an important radical source in the early morning (nighttime accumulation) and indeed throughout the day in the MCMA. Further we conclude that pollution export from the MCMA lowers radical production rates inside the basin. OVOC photolysis is a major radical source also in the urban outflow from the MCMA (Apel et al., 2010).

\section{Photolysis of $\mathrm{ClNO}_{2}$}

In Sect. 3.3.3 we estimated that heterogeneous $\mathrm{N}_{2} \mathrm{O}_{5}$ uptake to chloride containing aerosols can probably explain $\sim 10-15 \%$ of the observed $\mathrm{O}_{\mathrm{x}}$ loss at night, and leads to the accumulation of $2-3 \mathrm{ppb}$ of $\mathrm{ClNO}_{2}$ in the early morning. The photolysis of $\mathrm{ClNO}_{2}$ forms $\mathrm{Cl}$ radicals, which efficiently react with VOCs and OVOCs to form $\mathrm{RO}_{2}$ radicals in Mexico City $(\mathrm{Cl}$ addition is expected to be a minor pathway). We calculated J-values for $\mathrm{ClNO}_{2}$ from our spectroradiometer data, assuming a unity quantum yield for $\mathrm{Cl}$ radical production, and the absorption cross-section from Sander et al. (2006). Typical $\mathrm{J}\left(\mathrm{ClNO}_{2}\right)$ values during MCMA-2003 are $5 \times 10^{-5} \mathrm{~s}^{-1}$ at 07:00 a.m., $5 \times 10^{-4} \mathrm{~s}^{-1}$ at 09:00 a.m., and peak values are $\sim 9 \times 10^{-4} \mathrm{~s}^{-1}$ around solar noon. Assuming $2 \mathrm{ppb} \mathrm{ClNO}_{2}$, and $J\left(\mathrm{ClNO}_{2}\right)=6 \times 10^{-4} \mathrm{~s}^{-1}$, the rate of $\mathrm{Cl}$ and thus $\mathrm{RO}_{2}$ radical formation is estimated to be $2.3 \times 10^{7}$ molec $\mathrm{cm}^{-3} \mathrm{~s}^{-1}$. Based on this estimate, $\mathrm{ClNO}_{2}$ photolysis adds $50 \%$ to the presently accounted $\mathrm{RO}_{2}$ source, and corresponds to an extra $13 \%$ of $\Sigma \mathrm{OH}_{\text {new }}$ under midmorning conditions, and $\sim 15 \%$ at 07:00 a.m. Despite the abundance of other radical sources in the MCMA, $\mathrm{ClNO}_{2}$ photolysis seems to be relevant. A direct detection of $\mathrm{ClNO}_{2}$ is therefore desirable.

\section{Excited $\mathrm{NO}_{2}$ reaction with water}

If indeed operative, this reaction is not a significant source for $\mathrm{OH}$ radicals in the MCMA ( $\sim 2 \%$ on the 12-h daytime average radical production rate, see Table 1).

\subsection{Implications for Mexico City air quality}

The peak concentrations of secondary pollutants, such as $\mathrm{O}_{3}$ have decreased in recent years in Mexico City (Molina and Molina, 2002). It is presently not clear whether this is the result of (1) reductions in hydrocarbon emissions (VOC sensitivity of $\mathrm{O}_{3}$ production); (2) a delay in the formation of $\mathrm{O}_{3}\left(\mathrm{NO}_{\mathrm{x}}\right.$ suppressed $\mathrm{O}_{3}$ formation in the early morning); or (3) reductions in light intensity near ground as a result of increasing light-absorbing PM pollution; any combination is indeed possible. In any of these scenarios the formation of secondary pollutants is radical-limited. Figure 7 shows radical sources grouped into primary (emission related) and secondary (photochemistry related) radical sources. In light of the amplification of early morning sources by secondary pollutants, reactions of anthropogenic alkenes are found to be particularly important; a lower limit for the radical production rate related to alkenes (either directly or indirectly) is also included in Fig. 7. Reductions in VOC emissions (in particular alkenes) are expected to induce reductions in peak concentrations of secondary pollutants like $\mathrm{O}_{3}$ or SOA in three ways: (1) by lowering the rate of VOC oxidation as a result of a lower $\mathrm{VOC} / \mathrm{NO}_{\mathrm{x}}$ ratio (effect of a lower radical re-cycling efficiency); (2) by slowing down the formation of secondary pollutants (effect of a lower radical production rate during the day and at night); and (3) by delaying the onset of photochemical processing; peak concentrations of secondary pollutants are capped by pollution export from the MCMA (effect of reducing the time available to produce secondary pollutants), see Sect. 3.1. To our knowledge, only pathway (1) has previously been associated with VOC reductions, whereas pathways (2) and (3) reflect additional feedbacks that are demonstrated in this study.

In this context it is interesting to note that lower emission scenarios in Los Angeles (compare 2010 scenario in Griffin et al., 2004) yield lower total $\mathrm{RO}_{\mathrm{x}}$ production rates and a shift in the relative importance of individual pathways. An analysis of how different radical sources respond to changes in future emission scenarios is desirable also for Mexico City, where - for the above reasons - a strong coupling to VOC reductions can be expected.

\section{Conclusions and outlook}

A detailed chemical code has been constrained by an extensive set of observations to characterize radical sources in the MCMA. There are several conclusions from this study:

- The photolysis of secondary OVOC contributes about $47 \%$ to the $\mathrm{RO}_{\mathrm{x}}$ production on a 12 -h daytime average basis. OVOC other than $\mathrm{HCHO}$ are an important radical source despite the fact that (1) photolysis quantum yields of most carbonyls are significantly below unity, and (2) efficient pollution export in the afternoon has 


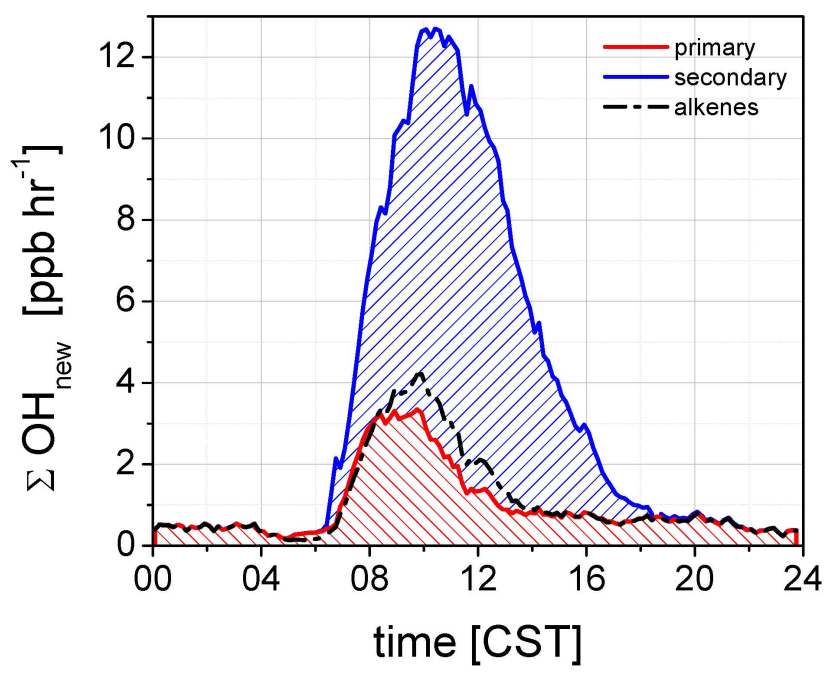

Fig. 7. The $\mathrm{OH}$-equivalent radical production rate grouped by primary (emission related) vs. secondary (photochemistry related) sources. Primary sources are taken as the sum of $\mathrm{O}_{3} /$ alkenes, primary $\mathrm{HCHO}$, the portion of PSS-HONO formed from primary radical sources, and alkene/ $\mathrm{NO}_{3}$ reactions. Secondary sources are taken as the photolysis of $\mathrm{O}_{3}$, other $\mathrm{HCHO}$, other OVOCs, the portion of PSS-HONO formed from secondary radical sources, unaccounted $\mathrm{HONO}$, and further $\mathrm{NO}_{3}$ reactions. The dashed-dot line represents a lower limit of the sum of primary and secondary $\Sigma \mathrm{OH}_{\text {new }}$ attributable to alkenes.

important feedbacks to lower radical production from secondary OVOC.

- Photo-induced formation of HONO contributes $<3 \%$ to the radical production rate around noontime; furthermore HONO photolysis is found to be faster than expected. The contribution of HONO can vary by location and/or the meteorological conditions.

- $\mathrm{ClNO}_{2}$ is likely a significant source of radicals in the MCMA; a direct detection of $\mathrm{ClNO}_{2}$ is desirable.

- Alkene reactions are indirectly responsible for $75 \%$ of the radical production rate in the early morning, and $30 \%$ of $\mathrm{OH}$ reactivity throughout the day. The reactivity of alkenes adds secondary VOC that accumulate in the mid morning boundary layer. In the MCMA radical production does not follow the abundance of sunlight, but rather peaks already during mid-morning, (around 10:00 a.m.), mostly due to $\mathrm{HCHO}, \mathrm{O}_{3}$ and secondary OVOC photolysis, reflecting how the trapping of pollutants within the MCMA basin accelerates radical production rates and thus photochemistry. Due to this reduced solar zenith angle dependence, high radical production rates are expected year-round.

- Anthropogenic alkenes add little organic mass to SOA, but indirectly add to SOA by reacting to produce radicals for the processing of other SOA precursor VOCs.
This indirect SOA contribution of alkenes, i.e., to significantly add to oxidant fields, is likely to be much larger than their direct contribution to SOA mass.

- Three pathways are identified by which reductions in VOC emissions (in particular alkenes) benefit reductions in peak concentrations of secondary pollutants such as $\mathrm{O}_{3}$ or SOA (see Sect. 3.7). The degree to which models could possibly capture the amplification of benefits from VOC reductions may depend on the level of detail represented in the respective underlying chemical codes. It remains to be verified whether important details such as radical production from $\mathrm{O}_{3} /$ alkene reactions are adequately represented in simplified chemical schemes that underlie the prediction of ozone and SOA in photochemical transport models.

- $\mathrm{NO}_{3} / \mathrm{VOC}$ reactions are found to contribute little to radical production at roof-top-level, but contribute to the removal of furanone-type and phenol-type compounds during the day, and are expected to gain relative importance in the photochemical plume downwind of the MCMA. We present, to our knowledge, the first direct observation of $\mathrm{NO}_{3}$ radicals in the urban center of a megacity.

- Future studies of radical sources in the polluted atmosphere need to take active measures to control the possibility of sampling artifacts with (1) the quantification of low $\mathrm{O}_{3}$ levels (Dunlea et al., 2006) which may bias any results related to alkenes, accomplished here by the direct detection of $\mathrm{O}_{3}$; and (2) alkene quantification and speciation by off-line analytical techniques (Atkinson et al., 1984; Jenkin et al., 2005), minimized here to the best possible degree by using a combination of an online FIS sensor, supplemented by VOC canister samples (Velasco et al., 2007). A direct confirmation of the alkene speciation by on-line techniques remains desirable in the MCMA.

- Finally, the current literature is biased towards observations made in air masses near the ground; little is known about how representative those observations are for the planetary boundary layer. Extrapolation from surface observations may not be straightforward due to the possibility of vertical gradients even during the day (Jobson et al., 2010); satellite data in turn provide only limited information about the vertical distribution of tracegases. Future efforts need to assess the vertical distribution of relevant radical precursors in the MCMA and throughout the troposphere.

Acknowledgements. We are grateful to Ulrich Platt for lending us the DOAS and spectroradiometer equipment. We thank Claudia Hak, Jens Bossmeyer and Kirsten Johnson for their help in setting up the instrument, staff at CENICA and at Museo Fuego Nuevo for their hospitality during the campaign, and colleagues at 
Forschungszentrum Juelich for helping with the spectroradiometer calibration, and Michael Trainer and Steve Brown for helpful comments. Financial support from National Science Foundation (ATM-0528227), Department of Energy (DE-FG02-0563980), Alliance for Global Sustainability (AGS), and Comisión Ambiental Metropolitana (CAM) is gratefully acknowledged. R. V. acknowledges consecutive fellowships by the Henry \& Camille Dreyfus Foundation and Alexander von Humboldt Foundation, and funding support from a CAREER award by the US National Science Foundation, award ATM-0847793.

Edited by: C. E. Kolb

\section{References}

Acker, K., Moller, D., Wieprecht, W., Meixner, F. X., Bohn, B., Gilge, S., Plass-Dulmer, C., and Berresheim, H.: Strong daytime production of $\mathrm{OH}$ from $\mathrm{HNO}_{2}$ at a rural mountain site, Geophys. Res. Lett., 33, L02809, doi:10.1029/2005GL024643, 2006.

Alicke, B., Geyer, A., Hofzumahaus, A., Holland, F., Konrad, S., Patz, H. W., Schafer, J., Stutz, J., Volz-Thomas, A., and Platt, U.: $\mathrm{OH}$ formation by HONO photolysis during the BERLIOZ experiment, J. Geophys. Res.-Atmos., 108, 8247-8263, 2003.

Alicke, B., Platt, U., and Stutz, J.: Impact of nitrous acid photolysis on the total hydroxyl radical budget during the Limitation of Oxidant Production/Pianura Padana Produzione di Ozono study in Milan, J. Geophys. Res.-Atmos., 107, 8196, doi:10.1029/2000JD000075, 2002.

Apel, E. C., Emmons, L. K., Karl, T., Flocke, F., Hills, A. J., Madronich, S., Lee-Taylor, J., Fried, A., Weibring, P., Walega, J., Richter, D., Tie, X., Mauldin, L., Campos, T., Weinheimer, A., Knapp, D., Sive, B., Kleinman, L., Springston, S., Zaveri, R., Ortega, J., Voss, P., Blake, D., Baker, A., Warneke, C., Welsh-Bon, D., de Gouw, J., Zheng, J., Zhang, R., Rudolph, J., Junkermann, W., and Riemer, D. D.: Chemical evolution of volatile organic compounds in the outflow of the Mexico City Metropolitan area, Atmos. Chem. Phys., 10, 2353-2375, doi:10.5194/acp-10-23532010, 2010.

Arens, F., Gutzwiller, L., Baltensperger, U., Gaggeler, H. W., and Ammann, M.: Heterogeneous reaction of $\mathrm{NO}_{2}$ on diesel soot particles, Environ. Sci. Technol., 35, 2191-2199, 2001.

Arnold, S. R., Chipperfield, M. P., Blitz, M. A., Heard, D. E., and Pilling, M. J.: Photodissociation of acetone: Atmospheric implications of temperature-dependent quantum yields, Geophys. Res. Lett., 31, L07110, doi:10.1029/2003GL019099, 2004.

Arriaga-Colina, J. L., West, J. J., Sosa, G., Escalona, S. S., Ordunez, R. M., and Cervantes, A. D. M.: Measurements of VOCs in Mexico City (1992-2001) and evaluation of VOCs and CO in the emissions inventory, Atmos. Environ., 38, 2523-2533, 2004.

Atkinson, R., Aschmann, S. M., Winer, A. M., and Pitts, J. N.: Gas-Phase Reaction of $\mathrm{NO}_{2}$ with Alkenes and Dialkenes, Int. J. Chem. Kinet., 16, 697-706, 1984.

Bass, A. M. and Paur, R. J.: Uv Absorption Cross-Sections for Ozone - the Temperature-Dependence, J. Photochem., 17, p. $141,1981$.

Bell, M. L., McDermott, A., Zeger, S. L., Samet, J. M., and Dominici, F.: Ozone and short-term mortality in 95 US urban communities, 1987-2000, Jama-J. Am. Med. Assoc., 292, 23722378, 2004.
Behnke, W., George, C., Scheer, V., and Zetzsch, C.: Production and decay of $\mathrm{CINO} 2$, from the reaction of gaseous $\mathrm{N}_{2} \mathrm{O}_{5}$ with $\mathrm{NaCl}$ solution: Bulk and aerosol experiments, J. Geophys. Res., 102, 3795-3804, 1997.

Bernath, P., Carleer, M., Fally, S., Jenouvrier, A., Vandaele, A. C., Hermans, C., Merienne, M. F., and Colin, R.: The Wulf bands of oxygen, Chem. Phys. Lett., 297, 293-299, 1998.

Bloss, C., Wagner, V., Bonzanini, A., Jenkin, M. E., Wirtz, K., Martin-Reviejo, M., and Pilling, M. J.: Evaluation of detailed aromatic mechanisms (MCMv3 and MCMv3.1) against environmental chamber data, Atmos. Chem. Phys., 5, 623-639, doi:10.5194/acp-5-623-2005, 2005a.

Bloss, C., Wagner, V., Jenkin, M. E., Volkamer, R., Bloss, W. J., Lee, J. D., Heard, D. E., Wirtz, K., Martin-Reviejo, M., Rea, G., Wenger, J. C., and Pilling, M. J.: Development of a detailed chemical mechanism (MCMv3.1) for the atmospheric oxidation of aromatic hydrocarbons, Atmos. Chem. Phys., 5, 641-664, doi:10.5194/acp-5-641-2005, 2005b.

Brown, S. S., Osthoff, H. D., Stark, H., Dube, W. P., Ryerson, T. B., Warneke, C., de Gouw, J. A., Wollny, A. G., Parrish, D. D., Fehsenfeld, F. C., and Ravishankara, A. R.: Aircraft observations of daytime $\mathrm{NO} 3$ and $\mathrm{N}_{2} \mathrm{O}_{5}$ and their implications for tropospheric chemistry, J. Photoch. Photobio. A, 176, 270-278, 2005.

Brown, S. S., Ryerson, T. B., Wollny, A. G., Brock, C. A., Peltier, R., Sullivan, A. P., Weber, R. J., Dube, W. P., Trainer, M., Meagher, J. F., Fehsenfeld, F. C., and Ravishankara, A. R.: Variability in nocturnal nitrogen oxide processing and its role in regional air quality, Science, 311, 67-70, 2006.

Cantrell, C. A., Davidson, J. A., Mcdaniel, A. H., Shetter, R. E., and Calvert, J. G.: Temperature-Dependent Formaldehyde CrossSections in the Near-Ultraviolet Spectral Region, J. Phys. Chem.US, 94, 3902-3908, 1990.

Carter, W. P. L.: Environmental Chamber Studies of Ozone Formation Potentials of Volatile Organic Compounds, in: Environmental Simulation Chambers: Application to Atmospheric Chemical Processes, edited by:Rudzinski, K. and Barnes, I., Proceedings of the NATO Advanced Research Workshop, Zakopane, Poland 1-4 October, 2004, NATO Sciences Series, IV. Earth and Environmental Sciences. Vol. 62. Kluwer Publishing, Doortrecht, The Netherlands, 2005.

Davis, D. L., Bell, M. L., and Fletcher, T.: A look back at the London smog of 1952 and the half century since, Environ. Health Persp., 110, A734-A735, 2002.

de Foy, B., Varela, J. R., Molina, L. T., and Molina, M. J.: Rapid ventilation of the Mexico City basin and regional fate of the urban plume, Atmos. Chem. Phys., 6, 2321-2335, doi:10.5194/acp-6-2321-2006, 2006.

Donaldson, D. J., Frost, G. J., Rosenlof, K. H., Tuck, A. F., and Vaida, V.: Atmospheric radical production by excitation of vibrational overtones via absorption of visible light, Geophys. Res. Lett., 24, 2651-2654, 1997.

Dunlea, E. J., Herndon, S. C., Nelson, D. D., Volkamer, R. M., Lamb, B. K., Allwine, E. J., Grutter, M., Ramos Villegas, C. R., Marquez, C., Blanco, S., Cardenas, B., Kolb, C. E., Molina, L. T., and Molina, M. J.: Technical note: Evaluation of standard ultraviolet absorption ozone monitors in a polluted urban environment, Atmos. Chem. Phys., 6, 3163-3180, doi:10.5194/acp6-3163-2006, 2006.

Dusanter, S., Vimal, D., Stevens, P. S., Volkamer, R., Molina, L. 
T., Baker, A., Meinardi, S., Blake, D., Sheehy, P., Merten, A., Zhang, R., Zheng, J., Fortner, E. C., Junkermann, W., Dubey, M., Rahn, T., Eichinger, B., Lewandowski, P., Prueger, J., and Holder, $\mathrm{H}$.: Measurements of $\mathrm{OH}$ and $\mathrm{HO}_{2}$ concentrations during the MCMA-2006 field campaign - Part 2: Model comparison and radical budget, Atmos. Chem. Phys., 9, 6655-6675, doi:10.5194/acp-9-6655-2009, 2009.

Dzepina, K., Volkamer, R. M., Madronich, S., Tulet, P., Ulbrich, I. M., Zhang, Q., Cappa, C. D., Ziemann, P. J., and Jimenez, J. L.: Evaluation of recently-proposed secondary organic aerosol models for a case study in Mexico City, Atmos. Chem. Phys., 9, 5681-5709, doi:10.5194/acp-9-5681-2009, 2009.

Emmerson, K. M., Carslaw, N., and Pilling, M. J.: Urban atmospheric chemistry during the PUMA campaign 2: Radical budgets for $\mathrm{OH}, \mathrm{HO}_{2}$ and $\mathrm{RO}_{2}$, J. Atmos. Chem., 52, 165-183, 2005.

Emmerson, K. M., Carslaw, N., Carslaw, D. C., Lee, J. D., McFiggans, G., Bloss, W. J., Gravestock, T., Heard, D. E., Hopkins, J., Ingham, T., Pilling, M. J., Smith, S. C., Jacob, M., and Monks, P. S.: Free radical modelling studies during the UK TORCH Campaign in Summer 2003, Atmos. Chem. Phys., 7, 167-181, doi:10.5194/acp-7-167-2007, 2007.

Fally, S., Vandaele, A. C., Carleer, M., Hermans, C., Jenouvrier, A., Merienne, M. F., Coquart, B., and Colin, R.: Fourier transform spectroscopy of the O-2 Herzberg bands. III. Absorption cross sections of the collision-induced bands and of the Herzberg continuum, J. Mol. Spectrosc., 204, 10-20, 2000.

Fayt, C. and van Roozendael, M.: WinDoas 2.1 - Software User Manual, Brussels: BIRA-IASB, 2001.

Finlayson-Pitts, B. J., Ezell, M. J., and Pitts Jr., J. N.: Formation of Chemically Active Chlorine Compounds by Reactions of Atmospheric $\mathrm{NaCl}$ Particles with Gaseous $\mathrm{N}_{2} \mathrm{O}_{5}$ and $\mathrm{ClONO}_{2}$, Nature, 337, 241-244, doi:10.1038/337241a0, 1989.

Fuhrer, J. and Booker, F.: Ecological issues related to ozone: agricultural issues, Environ. Int., 29, 141-154, 2003.

Frost, G. J., Trainer, M., Mauldin, R. L., Eisele, F. L., Prevot, A. S. H., Flocke, S. J., Madronich, S., Kok, G., Schillawski, R. D., Baumgardner, D., and Bradshaw, J.: Photochemical modeling of $\mathrm{OH}$ levels during the first aerosol characterization experiment (ACE 1), J. Geophys. Res.-Atmos., 104, 16041-16052, 1999.

Garcia, A. R., Volkamer, R., Molina, L. T., Molina, M. J., Samuelson, J., Mellqvist, J., Galle, B., Herndon, S. C., and Kolb, C. E.: Separation of emitted and photochemical formaldehyde in Mexico City using a statistical analysis and a new pair of gas-phase tracers, Atmos. Chem. Phys., 6, 4545-4557, doi:10.5194/acp-64545-2006, 2006.

Geyer, A., Alicke, B., Ackermann, R., Martinez, M., Harder, H., Brune, W., de Carlo, P., Williams, E., Jobson, T., Hall, S., Shetter, R., and Stutz, J.: Direct observations of daytime NO3: Implications for urban boundary layer chemistry, J. Geophys. Res.Atmos., 108, 4368, doi:10.1029/2002JD002967, 2003.

Gomer, T., Brauers, T., Heintz, F., Stutz, J., and Platt, U.: MFC User Manual, Version 1.98, Institut fuer Umweltphysik, University of Heidelberg, 1993.

Gregg, J. W., Jones, C. G., and Dawson, T. E.: Urbanization effects on tree growth in the vicinity of New York City, Nature, 424, 183-187, 2003.

Griffin, R. J.: Modeling the oxidative capacity of the atmosphere of the South Coast Air Basin of California. 2. HOx radical production, Environ. Sci. Technol. 38, 753-757, 2004.
Haagen-Smit, A. J., Darley, E. F., Zaitlin, M., Hull, H., and Nobel, W.: Investigation on injury to plants from air pollution in the Los Angeles area, Plant Physiol., 27, p. 18, 1951.

Hasson, A. S., Tyndall, G. S., and Orlando, J. J.: A product yield study of the reaction of $\mathrm{HO} 2$ radicals with ethyl peroxy (C2H5O2), acetyl peroxy $(\mathrm{CH} 3 \mathrm{C}(\mathrm{O}) \mathrm{O}-2)$, and acetonyl peroxy (CH3C(O)CH2O2) radicals, J. Phys. Chem. A, 108, 5979-5989, 2004.

Health Effects Institute: Reanalysis of the Harvard Six Cities Study and the American Cancer Society Study of Particulate Air Pollution and Mortality: A Special Report of the Institute's Particle Epidemiology Reanalysis Project. Library of Congress Catalog Number for the HEI Report Series: WA 754 R432, Health Effects Institute, Cambridge, MA, 2000.

IPCC: A Report of Working Group I of the Intergovernmental Panel on Climate Change: Summary for Policymakers, online available at: http://www.ipcc.ch/, 2007.

Jauregui, E.: Mexico City's urban heat island revisited, Erdkunde, 47, 185-195, 1993.

Jenkin, M. E., Andersen, M. P. S., Hurley, M. D., Wallington, T. J., Taketani, F., and Matsumi, Y.: A kinetics and mechanistic study of the $\mathrm{OH}$ and $\mathrm{NO} 2$ initiated oxidation of cyclohexa-1,3-diene in the gas phase, Phys. Chem. Chem. Phys., 7, 1194-1204, 2005.

Jenkin, M. E., Saunders, S. M., Wagner, V., and Pilling, M. J.: Protocol for the development of the Master Chemical Mechanism, MCM v3 (Part B): tropospheric degradation of aromatic volatile organic compounds, Atmos. Chem. Phys., 3, 181-193, doi:10.5194/acp-3-181-2003, 2003.

Jenouvrier, A., Merienne, M. F., Coquart, B., Carleer, M., Fally, S., Vandaele, A. C., Hermans, C., and Colin, R.: Fourier transform spectroscopy of the O-2 Herzberg bands - I. Rotational analysis, J. Mol. Spectrosc., 198, 136-162, 1999.

Jobson, B. T., Volkamer, R. A., Velasco, E., Allwine, G., Westberg, H., Lamb, B. K., Alexander, M. L., Berkowitz, C. M., and Molina, L. T.: Comparison of aromatic hydrocarbon measurements made by PTR-MS, DOAS and GC-FID during the MCMA 2003 Field Experiment, Atmos. Chem. Phys., 10, 1989-2005, doi:10.5194/acp-10-1989-2010, 2010.

Kleffmann, J., Gavriloaiei, T., Hofzumahaus, A., Holland, F., Koppmann, R., Rupp, L., Schlosser, E., Siese, M., and Wahner, A.: Daytime formation of nitrous acid: A major source of $\mathrm{OH}$ radicals in a forest, Geophys. Res. Lett., 32, L05818, doi:10.1029/2005GL022524, 2005.

Kleffmann, J., Lorzer, J. C., Wiesen, P., Kern, C., Trick, S., Volkamer, R., Rodenas, M., and Wirtz, K.: Intercomparison of the DOAS and LOPAP techniques for the detection of nitrous acid (HONO), Atmos. Environ., 40, 3640-3652, 2006.

Kraus, A., Rohrer, F., and Hofzumahaus, A.: Intercomparison of NO2 photolysis frequency measurements by actinic flux spectroradiometry and chemical actinometry during JCOM97, Geophys. Res. Lett., 27, 1115-1118, 2000.

Kurtenbach, R., Ackermann, R., Becker, K. H., Geyer, A., Gomes, J. A. G., Lorzer, J. C., Platt, U., and Wiesen, P.: Verification of the contribution of vehicular traffic to the total NMVOC emissions in Germany and the importance of the $\mathrm{NO}_{3}$ chemistry in the city air, J. Atmos. Chem., 42, 395-411, 2002.

Kwan, A. J., Crounse, J. D., Clarke, A. D., Shinozuka, Y., Anderson, B. E., Crawford, J. H., Avery, M. A., McNaughton, C. S., Brune, W. H., Singh, H. B., and Wennberg, P. O.: 
On the flux of oxygenated volatile organic compounds from organic aerosol oxidation, Geophys. Res. Lett., 33, L15815, doi:10.1029/2006GL026144, 2006.

Lei, W., de Foy, B., Zavala, M., Volkamer, R., and Molina, L. T.: Characterizing ozone production in the Mexico City Metropolitan Area: a case study using a chemical transport model, Atmos. Chem. Phys., 7, 1347-1366, doi:10.5194/acp-7-1347-2007, 2007.

Lei, W., Zavala, M., de Foy, B., Volkamer, R., and Molina, L. T.: Characterizing ozone production and response under different meteorological conditions in Mexico City, Atmos. Chem. Phys., 8, 7571-7581, doi:10.5194/acp-8-7571-2008, 2008.

Lei, W., Zavala, M., de Foy, B., Volkamer, R., Molina, M. J., and Molina, L. T.: Impact of primary formaldehyde on air pollution in the Mexico City Metropolitan Area, Atmos. Chem. Phys., 9, 2607-2618, doi:10.5194/acp-9-2607-2009, 2009.

Li, G., Lei, W., Zavala, M., Volkamer, R., Dusanter, S., Stevens, P., and Molina, L. T.: Impacts of HONO sources on the photochemistry in Mexico City during the MCMA-2006/MILAGO Campaign, Atmos. Chem. Phys., 10, 6551-6567, doi:10.5194/acp10-6551-2010, 2010.

Li, S. P., Matthews, J., and Sinha, A.: Atmospheric hydroxyl radical production from electronically excited $\mathrm{NO}_{2}$ and $\mathrm{H}_{2} \mathrm{O}$, Science, 319, 1657-1660, 2008.

Martinez, M., Harder, H., Kovacs, T. A., Simpas, J. B., Bassis, J., Lesher, R., Brune, W. H., Frost, G. J., Williams, E. J., Stroud, C. A., Jobson, B. T., Roberts, J. M., Hall, S. R., Shetter, R. E., Wert, B., Fried, A., Alicke, B., Stutz, J., Young, V. L., White, A. B., and Zamora, R. J.: OH and $\mathrm{HO} 2$ concentrations, sources, and loss rates during the Southern Oxidants Study in Nashville, Tennessee, summer 1999, J. Geophys. Res.-Atmos., 108, 46174633, 2003.

Merienne, M. F., Jenouvrier, A., Coquart, B., Carleer, M., Fally, S., Colin, R., Vandaele, A. C., and Hermans, C.: Fourier transform spectroscopy of the O-2 Herzberg bands - II. Band oscillator strengths and transition moments, J. Mol. Spectrosc., 202, 171-193, 2000.

Merienne, M. F., Jenouvrier, A., Coquart, B., Carleer, M., Fally, S., Colin, R., Vandaele, A. C., and Hermans, C.: Improved data set for the Herzberg band systems of O-16(2), J. Mol. Spectrosc., 207, 120-120, 2001.

Molina, L. T. and Molina, M. J.: Air Quality in the Mexico Megacity: An Integrated Assessment, Kluwer Academic Publishers, Dordrecht, The Netherlands, 105-136, 2002.

Molina, L. T., Kolb, C. E., de Foy, B., Lamb, B. K., Brune, W. H., Jimenez, J. L., Ramos-Villegas, R., Sarmiento, J., ParamoFigueroa, V. H., Cardenas, B., Gutierrez-Avedoy, V., and Molina, M. J.: Air quality in North America's most populous city overview of the MCMA-2003 campaign, Atmos. Chem. Phys., 7, 2447-2473, doi:10.5194/acp-7-2447-2007, 2007.

Molina, L. T., Madronich, S., Gaffney, J. S., Apel, E., de Foy, B., Fast, J., Ferrare, R., Herndon, S., Jimenez, J. L., Lamb, B., Osornio-Vargas, A. R., Russell, P., Schauer, J. J., Stevens, P. S., and Zavala, M.: An overview of the MILAGRO 2006 campaign: Mexico City emissions and their transport and transformation, Atmos. Chem. Phys. Discuss., 10, 7819-7983, doi:10.5194/acpd-10-7819-2010, 2010.

Nel, A.: Air Pollution-Related Illness: Effects of Particles, Science, 308, 804-806, 2005.
Oke, T. R., Spronken-Smith, R. A., Jauregui, E., and Grimmond, C. S. B.: The energy balance of central Mexico City during the dry season, Atmos. Environ., 33, 3919-3930, 1999.

Orphal, J.: A critical review of the absorption cross-sections of $\mathrm{O}_{3}$ and $\mathrm{NO}_{2}$ in the ultraviolet and visible, J. Photoch. Photobio. A, 157, 185-209, 2003.

PAPA, Public Health and Air Pollution in Asia (PAPA) Special Report 15: Health Effects of Outdoor Air Pollution in Developing Countries of Asia. Library of Congress Catalog Number for the HEI Report Series: WA 754 R432, Health Effects Institute, Cambridge, MA, 2004.

Platt, U.: Differential Optical Absorption Spectroscopy, in Monitoring by Spectroscopic Techniques, edited by M. W. Sigrist, Wiley \& Sons, New York, 27-84, 1994.

Platt, U., Perner, D., Harris, G. W., Winer, A. M., and Pitts, J. N.: Observations of Nitrous-Acid in An Urban Atmosphere by Differential Optical-Absorption, Nature, 285, 312-314, 1980.

Pope, C. A., Burnett, R. T., Thun, M. J., Calle, E. E., Krewski, D., Ito, K., and Thurston, G. D.: Lung cancer, cardiopulmonary mortality, and long-term exposure to fine particulate air pollution, Jama-J. Am. Med. Assoc., 287, 1132-1141, 2002.

Ramanathan, V., Crutzen, P. J., Kiehl, J. T., and Rosenfeld, D.: Aerosols, Climate, and the Hydrological Cycle, Science, 294, 2119-2124, 2001.

Ramazan, K. A., Wingen, L. M., Miller, Y., Chaban, G. M., Gerber, R. B., Xantheas, S. S., and Finlayson-Pitts, B. J.: New experimental and theoretical approach to the heterogeneous hydrolysis of NO2: Key role of molecular nitric acid and its complexes, J. Phys. Chem. A, 110, 6886-6897, 2006.

Ren, X. R., Harder, H., Martinez, M., Lesher, R. L., Oliger, A., Simpas, J. B., Brune, W. H., Schwab, J. J., Demerjian, K. L., He, Y., Zhou, X. L., and Gao, H. G.: OH and HO2 Chemistry in the urban atmosphere of New York City, Atmos. Environ., 37, 3639-3651, 2003.

Roberts, J. M., Osthoff, H. D., Brown, S. S., and Ravishankara, A. R.: $\mathrm{N}_{2} \mathrm{O}_{5}$ oxidizes chloride to $\mathrm{Cl}_{2}$ in acidic atmospheric aerosol, Science, 321, p. 1059, 2008.

Robinson, A. L., Donahue, N. M., Shrivastava, M. K., Weitkamp, E. A., Sage, A. M., Grieshop, A. P., Lane, T. E., Pierce, J. R., and Pandis, S. N.: Rethinking organic aerosols: Semivolatile emissions and photochemical aging, Science, 315, 1259-1262, 2007.

Ruiz-Suarez, L. G., Castro, T., Mar, B., Ruiz-Santoyo, M. E., and Cruz, X.: Do We Need An Ad Hoc Chemical Mechanism for Mexico-City Photochemical Smog, Atmos. Environ. A-Gen., 27, 405-425, 1993.

Salcedo, D., Onasch, T. B., Dzepina, K., Canagaratna, M. R., Zhang, Q., Huffman, J. A., DeCarlo, P. F., Jayne, J. T., Mortimer, P., Worsnop, D. R., Kolb, C. E., Johnson, K. S., Zuberi, B., Marr, L. C., Volkamer, R., Molina, L. T., Molina, M. J., Cardenas, B., Bernabé, R. M., Márquez, C., Gaffney, J. S., Marley, N. A., Laskin, A., Shutthanandan, V., Xie, Y., Brune, W., Lesher, R., Shirley, T., and Jimenez, J. L.: Characterization of ambient aerosols in Mexico City during the MCMA-2003 campaign with Aerosol Mass Spectrometry: results from the CENICA Supersite, Atmos. Chem. Phys., 6, 925-946, doi:10.5194/acp-6-9252006, 2006.

Sander, S. P., Friedl, R. R., Golden, D. M., Kurylo, M. J., Moortgat, G. K., Keller-Rudeck, H., Wine, P. H., Ravishankara, A. R., Kolb, C. E., Molina, M. J., Finlaysson-Pitts, B. J., Huie, R. E., 
and Orkin, R. L.: Chemical Kinetics and Photochemical Data for Use in Atmospheric Studies Evaluation Number 15, JPL Publication, 06-2, 1-522, 2006.

Saunders, S. M., Jenkin, M. E., Derwent, R. G., and Pilling, M. J.: Protocol for the development of the Master Chemical Mechanism, MCM v3 (Part A): tropospheric degradation of nonaromatic volatile organic compounds, Atmos. Chem. Phys., 3, 161-180, doi:10.5194/acp-3-161-2003, 2003.

Sheehy, P. M., Volkamer, R., Molina, L. T., and Molina, M. J.: Oxidative capacity of the Mexico City atmosphere - Part 2: A $\mathrm{RO}_{\mathrm{X}}$ radical cycling perspective, Atmos. Chem. Phys., 10, 69937008, doi:10.5194/acp-10-6993-2010, 2010.

Shirley, T. R., Brune, W. H., Ren, X., Mao, J., Lesher, R., Cardenas, B., Volkamer, R., Molina, L. T., Molina, M. J., Lamb, B., Velasco, E., Jobson, T., and Alexander, M.: Atmospheric oxidation in the Mexico City Metropolitan Area (MCMA) during April 2003, Atmos. Chem. Phys., 6, 2753-2765, doi:10.5194/acp-62753-2006, 2006.

Singh, H. B., Kanakidou, M., Crutzen, P. J., and Jacob, D. J.: HighConcentrations and Photochemical Fate of Oxygenated Hydrocarbons in the Global Troposphere, Nature, 378, 50-54, 1995.

Stemmler, K., Ammann, M., Donders, C., Kleffmann, J., and George, C.: Photosensitized reduction of nitrogen dioxide on humic acid as a source of nitrous acid, Nature, 440, 195-198, 2006.

Stephens, S., Madronich, S., Wu, F., Olson, J. B., Ramos, R., Retama, A., and Muñoz, R.: Weekly patterns of México City's surface concentrations of $\mathrm{CO}, \mathrm{NO}_{\mathrm{x}}, \mathrm{PM}_{10}$ and $\mathrm{O}_{3}$ during 19862007, Atmos. Chem. Phys., 8, 5313-5325, doi:10.5194/acp-85313-2008, 2008.

Stutz, J., Alicke, B., Ackermann, R., Geyer, A., Wang, S. H., White, A. B., Williams, E. J., Spicer, C. W., and Fast, J. D.: Relative humidity dependence of HONO chemistry in urban areas, J. Geophys. Res.-Atmos., 109, D03307, doi:10.1029/2003JD004135, 2004.

Stutz, J., Kim, E. S., Platt, U., Bruno, P., Perrino, C., and Febo, A.: UV-visible absorption cross sections of nitrous acid, J. Geophys. Res.-Atmos., 105, 14585-14592, 2000.

Vandaele, A. C., Simon, T., Giolmont, J., Carleer, C., and Colin, R.: $\mathrm{SO}_{2}$ absorption cross section measurement in the UV using fourier transform spectrometer, J. Geophys. Res., 99, 2559925605, 1994.

Velasco, E., Lamb, B., Westberg, H., Allwine, E., Sosa, G., ArriagaColina, J. L., Jobson, B. T., Alexander, M. L., Prazeller, P., Knighton, W. B., Rogers, T. M., Grutter, M., Herndon, S. C., Kolb, C. E., Zavala, M., de Foy, B., Volkamer, R., Molina, L. T., and Molina, M. J.: Distribution, magnitudes, reactivities, ratios and diurnal patterns of volatile organic compounds in the Valley of Mexico during the MCMA 2002 \& 2003 field campaigns, Atmos. Chem. Phys., 7, 329-353, doi:10.5194/acp-7-329-2007, 2007.

Volkamer, R., Etzkorn, T., Geyer, A., and Platt, U.: Correction of the oxygen interference with UV spectroscopic (DOAS) measurements of monocyclic aromatic hydrocarbons in the atmosphere, Atmos. Environ., 32, 3731-3747, 1998.

Volkamer, R., Platt, U., and Wirtz, K.: Primary and Secondary Glyoxal Formation from Aromatics: Experimental Evidence for the Bicycloalkyl-Radical Pathway from Benzene, Toluene, and pXylene, J. Phys. Chem. A, 105, 7865-7874, 2001.
Volkamer, R., Molina, L. T., Molina, M. J., Shirley, T., and Brune, W. H.: DOAS measurement of glyoxal as an indicator for fast VOC chemistry in urban air, Geophys. Res. Lett., 32, L08806, doi:10.1029/2005GL022616, 2005a.

Volkamer, R., Spietz, P., Burrows, J. P., and Platt, U.: Highresolution absorption cross-section of Glyoxal in the UV/vis and IR spectral ranges, J. Photoch. Photobio. A, 172, 35-46, 2005 b.

Volkamer, R., Jimenez, J. L., San Martini, F., Dzepina, K., Zhang, Q., Salcedo, D., Molina, L. T., Worsnop, D. R., and Molina, M. J.: Secondary organic aerosol formation from anthropogenic air pollution: Rapid and higher than expected, Geophys. Res. Lett., 33, L17811, doi:10.1029/2006GL026899, 2006.

von Friedeburg, C., Wagner, T., Geyer, A., Kaiser, N., Vogel, B., Vogel, H., and Platt, U.: Derivation of tropospheric $\mathrm{NO}_{3}$ profiles using off-axis differential optical absorption spectroscopy measurements during sunrise and comparison with simulations, J. Geophys. Res.-Atmos., 107, 4168, doi:10.1029/2001JD000481, 2002.

Wall, K. J., Schiller, C. L., and Harris, G. W.: Measurements of the HONO photodissociation constant, J. Atmos. Chem., 55, 31-54, 2006.

West, J. J., Zavala, M. A., Molina, L. T., Molina, M. J., San Martini, F., McRae, G. J., Sosa-Iglesias, G., and Arriaga-Colina, J. L.: Modeling ozone photochemistry and evaluation of hydrocarbon emissions in the Mexico City metropolitan area, J. Geophys. Res.-Atmos., 109, D19312, doi:10.1029/2004JD004614, 2004.

Witonsky, S. K., Canagaratna, M. R., Coy, S. L., Steinfeld, J. I., Field, R. W., and Kachanov, A. A.: The 3 nu(1) overtone band of trans-nitrous acid: Rotational and perturbation analysis and absolute intensity, J. Chem. Phys., 115, 3134-3143, 2001.

Zavala, M., Herndon, S. C., Slott, R. S., Dunlea, E. J., Marr, L. C., Shorter, J. H., Zahniser, M., Knighton, W. B., Rogers, T. M., Kolb, C. E., Molina, L. T., and Molina, M. J.: Characterization of on-road vehicle emissions in the Mexico City Metropolitan Area using a mobile laboratory in chase and fleet average measurement modes during the MCMA-2003 field campaign, Atmos. Chem. Phys., 6, 5129-5142, doi:10.5194/acp-6-5129-2006, 2006.

Zhang, Q., Jimenez, J. L., Canagaratna, M. R., Allan, J. D., Coe, H., Ulbrich, I., Alfarra, M. R., Takami, A., Middlebrook, A. M., Sun, Y. L., Dzepina, K., Dunlea, E., Docherty, K., deCarlo, P. F., Salcedo, D., Onasch, T., Jayne, J. T., Miyoshi, T., Shimono, A., Hatakeyama, S., Takegawa, N., Kondo, Y., Schneider, J., Drewnick, F., Borrmann, S., Weimer, S., Demerjian, K., Williams, P., Bower, K., Bahreini, R., Cottrell, L., Griffin, R. J., Rautiainen, J., Sun, J. Y., Zhang, Y. M., and Worsnop, D. R.: Ubiquity and dominance of oxygenated species in organic aerosols in anthropogenically-influenced Northern Hemisphere midlatitudes, Geophys. Res. Lett., 34, L13801, doi:10.1029/2007GL029979, 2007.

Zhou, X. L., Civerolo, K., Dai, H. P., Huang, G., Schwab, J., and Demerjian, K.: Summertime nitrous acid chemistry in the atmospheric boundary layer at a rural site in New York State, J. Geophys. Res.-Atmos., 107, 4590, doi:10.1029/2001JD001539, 2002. 